\title{
Capturing the needs of architects: a survey of their current information requirements for natural ventilation design
}

\author{
R. Baeumle ${ }^{\mathrm{a}}$ and G.R. Hunt ${ }^{\mathrm{a},}{ }^{*}$ \\ ${ }^{a}$ Department of Engineering, University of Cambridge, Trumpington Street, Cambridge, CB2 \\ 1PZ, United Kingdom
}

\author{
ARTICLE HISTORY \\ Compiled August 8, 2017
}

\begin{abstract}
This paper focusses on identifying the information needs of modern-day architects seeking to design low-energy naturally ventilated buildings. We present the results of a survey conveying the personal views of international MA/MSc/MArch student architects at the Architectural Association School of Architecture, London, UK. The aim was to gain insight and raise awareness of architects' current information requirements. Our study covered aspects concerning architects' perceived knowledge of natural ventilation, the resources they most frequently use/refer to (and prefer to use) for design guidance, their perceived barriers when designing for natural ventilation, and their preference for the style and format for future natural ventilation design guides. Our results reveal that design codes and case studies of exemplar buildings, rather than technically-orientated journals, were the preferred literature. A need for architect-focussed design guidance, in a visual format using conventions and terminologies already familiar to, or readily appreciated by, architects was identified.
\end{abstract}

\section{KEYWORDS}

Survey; natural ventilation; architecture; design guidance; low-energy building design

\section{Introduction}

Concerns about global warming and the basic desire to conserve the world's resources have contributed to a reawakened interest in and demand for naturally ventilated buildings. The challenge from a design perspective is clear and centres around harnessing the natural forces of wind and thermal energy to ventilate indoor spaces. Arguably, demand has outstripped our understanding of how these buildings truly operate and a number of open questions regarding establishing and controlling airflows in naturally ventilated spaces have motivated considerable, and indeed ongoing, research. Certainly within the academic literature, the growth of interest in natural ventilation is strikingly evident. Over the past thirty years, for example, there has been in excess of a five-fold increase in the annual number of peer-reviewed documents published on the topic. An indication of this trend is evident in Figure 1 which plots the number of documents, ${ }^{1}$ published worldwide between 1986 and 2016, with both 'natural ventilation' and 'building' appearing in the title, abstract or keywords. 


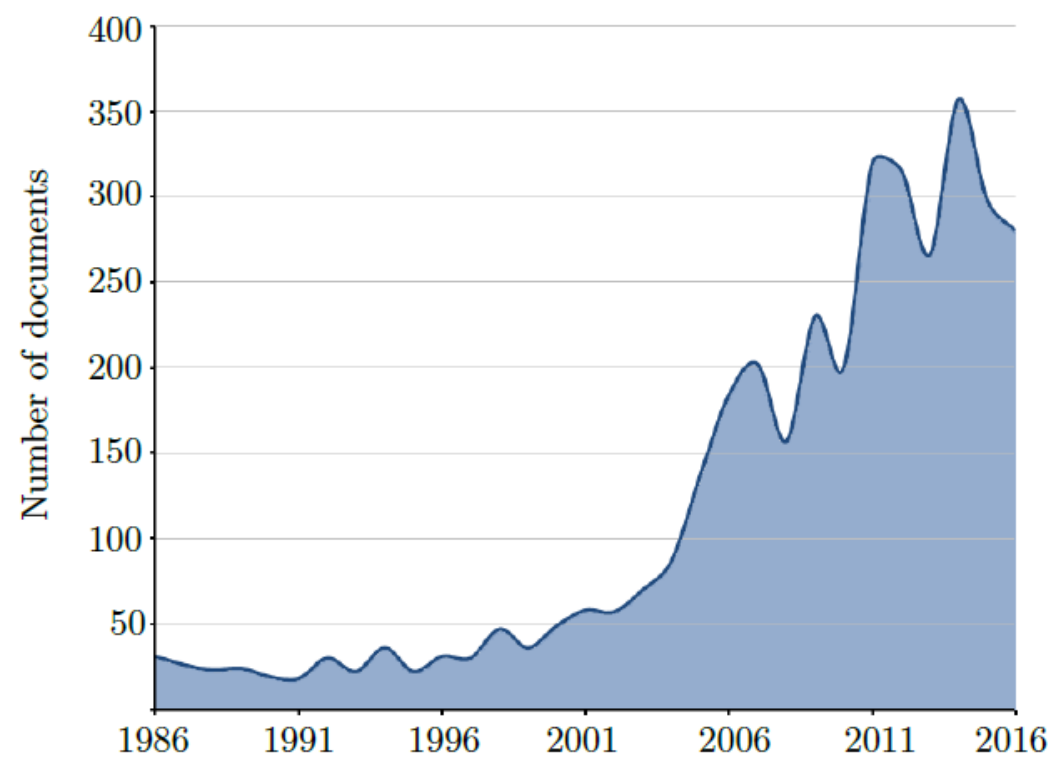

Figure 1.: The number of documents published on the topic of natural ventilation between 1986 and 2016. Documents include articles, conference papers and books (Graph credit: Scopus (2017)).

Used as part of a sustainable building design and operating strategy, natural ventilation has already been proven to be an effective approach for reducing the energy consumption of buildings while delivering the required ventilation and comfort. By naturally ventilating rather than air-conditioning, Baker \& Steemers (2000) found that offices consumed $60 \%$ less energy on average. The Frederick Lanchester Library in Coventry, UK, is an example of a naturally ventilated building that has been shown by Krausse et al. (2007) to consume less than half the energy of an equivalent mechanically ventilated building. The $\mathrm{CH} 2$ Building in Melbourne, Australia - which exploits a mixed-mode ventilation system - has been awarded a six Green Star 'As Built' rating and is in the top $20 \%$ of buildings for occupant satisfaction in Australia (Birt \& Newsham, 2009), further highlighting the capacity of these modern buildings to deliver a thermally comfortable and healthy indoor environment, naturally.

In order to design well-performing and energy-efficient naturally ventilated buildings, architects (and indeed ventilation engineers and consultants) require information on ventilation principles that is intuitive and accessible. Ideally, the information needs to be coupled with guidance for ventilation in a form that enables a rapid and straightforward first-order predictive capability so that vent areas, indoor temperatures and airflow rates can be estimated, the design assessed, modified and reassessed.

High-quality, unambiguous and accurate information is essential, particularly as early stage decisions made by the architect (or others) are often carried through the design process (Ellis \& Mathews, 2001). As a consequence, poor, incomplete, unclear or misunderstood information could have potentially detrimental implications to the overall building design and its performance. Incongruity between theories and definitions used by the research community (and in practice) can further exacerbate the issue as an architect who draws from the open literature is forced to decide on which information to trust and apply to achieve their design. 
Regarding the latter, even within the well-established engineering/scientific communities there can be considerable variation between the definition and interpretation of certain terminologies. As an example, Jones et al. (2016) recently highlighted different, and even contradictory, definitions regarding the area of ventilation openings that are currently used by building standards, guidelines, textbooks and software tools. Confusion, in this case, over terms including 'free area', 'equivalent area' and 'effective area', can lead to unintended and undesirable errors in design specifications, leading (in turn) to under (or over) ventilation, overheating, air quality and acoustic issues, excessive energy consumption and associated carbon emissions, and high capital running costs (Jones et al. 2016).

Whilst tremendous advances have been made over the past two to three decades in the science underlying and explaining natural ventilation, advances that have strong implications for effective design, the bulk of this material is published in scientific journals, rather than in the literature more familiar to, and accessible by, the architectural community. Ironically, even the most recent of these advances may require many years to filter through to the architectural community who, arguably, stand to benefit most directly from them. At best then, a delay is to be expected between a given advancement and its practical uptake and, at worst, the highly technical nature and terminology used in the scientific literature that conveys these advancements may present an impasse to knowledge transfer between scientific and architectural communities.

Motivated by a desire to improve the transfer of information from the technical journals to practising architects, we conducted a survey on a group of $33 \mathrm{MA} / \mathrm{MSc} / \mathrm{MArch}$ student architects at the Architectural Association (AA) in London. Their personal views and experiences were collected via a bespoke questionnaire that we designed specifically to gain direct insight into the needs of young architects. Rather than attempting to make any preconceived expectation regarding what architects 'should need to know', we designed the survey to be a 'sounding board' for architects' opinions; their opinions were sought on a range of natural ventilation design specific matters, including on their vision for the types and styles of information they would like to have at their fingertips.

This paper presents the results of our questionnaire. The collated views and needs of young architects are highlighted using visual charts and tables. Our findings are potentially of interest to those engaged in sustainable building design, whether as practitioners or academics, from architectural, building services or wider engineering or scientific backgrounds. Moreover, we anticipate that our findings may prove of interest to those aiming to promote a wider uptake of technical information on natural ventilation by architects.

The structure of this paper is as follows. In $\$ 2$ we describe the methodology we chose and the rationale for the line of enquiry (and grouping of questions into themes) that underpinned our questionnaire. We overview the key findings from our survey in $\$ 3$, and based on this we offer recommendations for writing/presentation styles for technical practitioners (4) that potentially better engage architects with scientific information. Finally, we draw our conclusions in $\$$ and discuss the limitations of our survey. 


\section{Method of enquiry}

The questionnaire was administered to the group of $33 \mathrm{MA} / \mathrm{MSc} / \mathrm{MArch}$ student architects, aged between 20 and 30 years, in their lecture room on campus during class time in order to ensure a $100 \%$ response rate. The questionnaire was completed by all and each questionnaire was collected personally by the authors before the students left. Gathering respondents in a group setting and personally distributing the questionnaire - as opposed to electronic mailing - has already been proven to be a highly-effective approach to increase the motivation of participants to respond (Adler \& Clark, 2014 Hinrichs \& Gatewood, 1967; Wood, 2003). Moreover, this setting also provided the authors with the opportunity to explain the purpose of the investigation. In our survey, the incentive offered for participating was the opportunity to influence the future development of natural ventilation design guidance that better addresses the needs of architects.'

We conducted our survey on these MA/MSc/MArch students as they were each engaged in their own personal design projects at the time of our study, and hence, were anticipated to provide a realistic snapshot of architects' information needs and requirements in the context of a natural ventilation design. Whilst we did not explicitly question the students regarding their previous professional experience, many we questioned had previous experience working in an architectural practice as this is a requirement in many architectural schools. ${ }^{2}$ In the UK, for example, students take a full year out for practical training as part of their undergraduate course.

The questionnaire, totalling 25 questions, consisted of both closed-ended and openended questions (Q1-Q25, see Appendix). Closed-ended questions invited a response that fits a preordained answer (e.g. Q1, Q2, Q6), whereas open-ended questions (e.g. Q5, Q10, Q15, Q25) demanded answers in terms of the respondent's own opinion, belief or judgement. The primary objectives of the survey were to:

- determine the students' perceived understanding of natural ventilation;

- detect if there were any recurring gaps in understanding;

- discover whether they intend to use, or have used, natural ventilation strategies in their building design projects;

- discern the common types of resource they exploit for design guidance;

- determine the perceived barriers hindering or preventing them from adopting a natural ventilation strategy in their designs; and

- distinguish ideal (or highly desired) presentation formats of design information for architects.

In light of these objectives, the questions posed centred around a number of main themes as illustrated by the flow chart in Figure 2 and as described below.

Theme 1 opened the questionnaire by asking the academic route the students' took for their secondary and tertiary education;

Theme 2 investigated their preferred types of resource to use at the early stage of a natural ventilation design (in this case, for their studio-based projects), and whether they would consider seeking technical, or other related advice, from different professions (e.g. academics involved in low-energy building ventilation research, or engineers and architects working in industry/practices);

Theme 3 covered questions regarding their perceived knowledge of natural ventilation theory;

Theme 4 examined their concerns, if any, regarding the application of natural ventilation 
theory into design practice (e.g. the sizing of vents necessary to achieve a desired airflow rate);

Theme 5 investigated how they perceive air to flow through openings made in the façade of a naturally ventilated space by asking them to sketch 'airflow arrows'. This theme also questioned their views on the use of simplified schematics to represent a building or space as commonly used in the mathematical modelling of flows in naturally ventilated spaces;

Theme 6 probed the barriers (perceived or otherwise) to their designing naturally ventilated buildings;

Theme 7 enquired whether an increase in the demand for low-energy buildings in the near future was perceived; and finally,

Theme 8 closed the questionnaire by enquiring as to their preferred format, style and level of detail for future natural ventilation design guidance for architects.

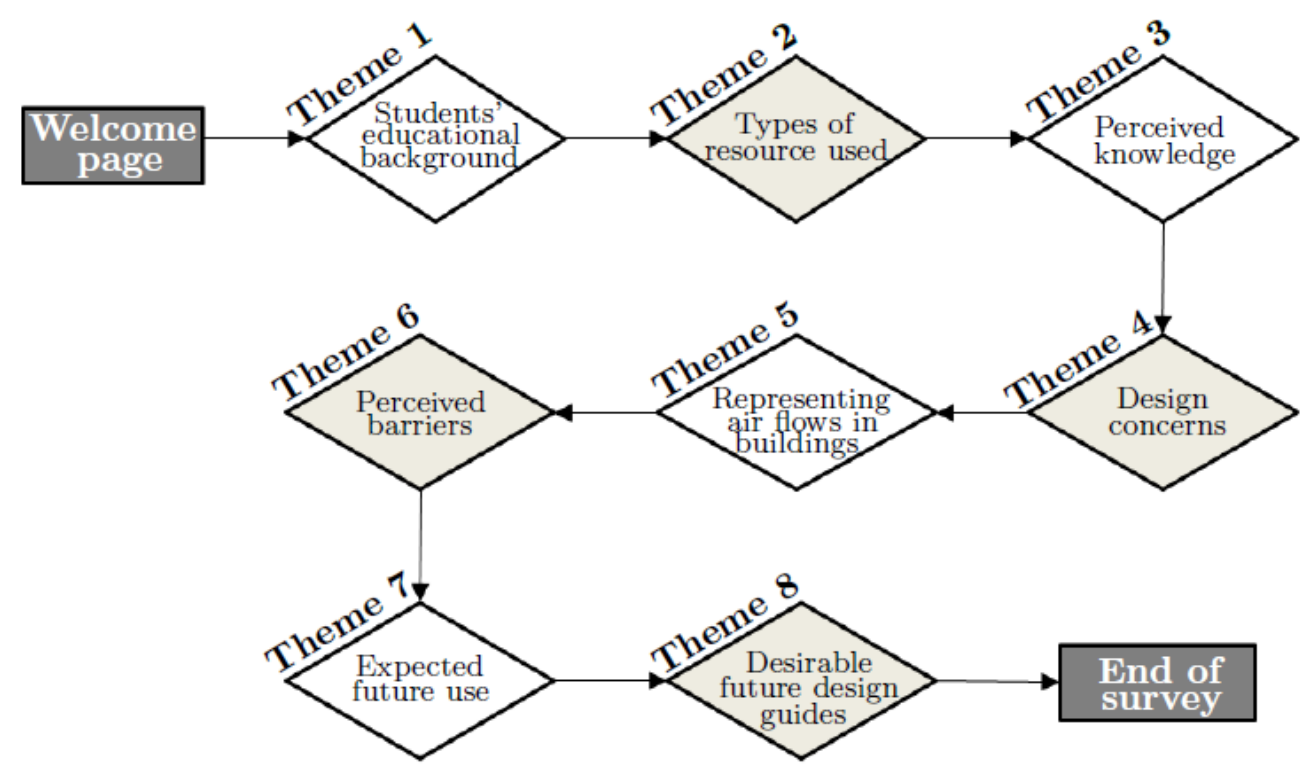

Figure 2.: Flow chart showing the eight themes covered by our questionnaire.

At this stage, it is worth noting that the intention behind our investigation was not to serve as an opinion poll for justifying the use (or otherwise) of natural ventilation in buildings, nor can it be regarded as a representative sample of the viewpoints of all architects - the latter due, for example, to the limited sample size and experience-base of those completing the questionnaire. Moreover, the responses of the group surveyed are likely to be influenced by their current course tutors, for example, in terms of their preferences for specific publication sources that are relevant to the topics taught in the syllabus. The data collected and the comments presented herein (e.g. those expressing opinions of the respondents) are therefore not meant to be subjected to the rigours and tests of statistical significance, but crucially may be regarded as a snapshot of the views and a window into the needs of future architects. 


\section{Overview}

The responses to our questionnaire are grouped and summarised below ( $3.1-\$ 3.5$ and some implications of the findings are discussed. We include written responses (in quotation marks) that proved to be particularly pertinent, insightful or informative. The key result which emerged under each subheading below, and that is singled out for attention here, is highlighted in bold.

\subsection{Resources commonly used for design guidance}

The most preferred type of design guidance was case studies of exemplar naturally ventilated buildings.

The participants were asked to select, from a variety of resources, their preferred type of guidance for natural ventilation design. Choices ranged from the traditional print resources, e.g. journal papers, to potentially more subjective approaches, e.g. relying on experience or the incorporation of a design feature/element/approach that they perceived was expected. The radar chart shown in Figure 3 captures their responses.

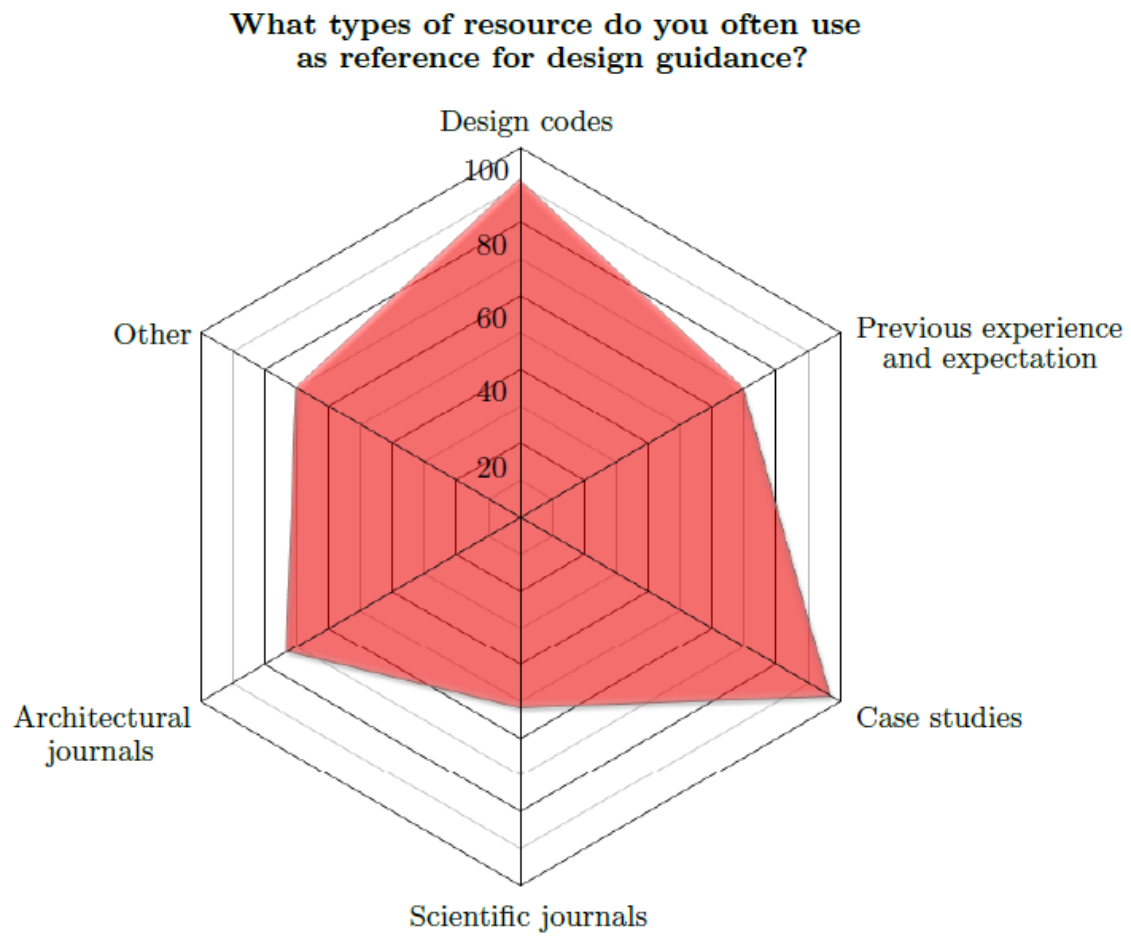

Figure 3.: Radar chart showing the preference for particular types of resource for guidance in a natural ventilation design. Percentages shown against a given resource represent the number of votes received divided by the total number (33) of participants.

An overwhelming $97 \%$ preferred to use case studies of already built naturally ventilated buildings as a reference point for guidance in design. A possible reason behind this preference may be the fact that case studies provide the evidence-based reassurance which can demonstrate, qualitatively, a specific design strategy is performing effectively. 
Evidently, reference to design codes and to building standards (e.g. ASHRAE Standard 55 (ASHRAE, 2010), CIBSE AM 10 (CIBSE, 2005)), reliance on personal experience and expectation, and the use of architectural journals (e.g. Architectural Science Review; ISSN: 0003-8628) are also commonplace when they considered designing naturally ventilated buildings. Almost one third of the students stated that they subscribe to the Architects' Journal (ISSN: 0003-8466), a weekly non-peer reviewed architectural magazine ${ }^{3}$ published in London. Somewhat unexpectedly, reference to these sources far exceed those made to scientific articles on natural ventilation flows and airflow control that are widely published in the open literature.

Proceedings of PLEA and articles published in the journals 'Building and Environment' and 'Energy and Buildings' were most frequently read and with the greatest interest.

We wanted to discern the types of journal papers and conference proceedings that architectural students are interested in reading. Clearly this information may prove helpful when selecting an avenue for the publication of a particular new finding so as to ensure it hits the target audience. Moreover, this information may also be of use to publishing bodies themselves.

A choice of eight different journals, regarded as either of a technical, an interdisciplinary or a design-related nature, were given in the questionnaire. The radar charts, Figures $4(\mathrm{a}, \mathrm{b})$, highlight those journals most frequently read and those which instigated most interest in reading, respectively.

(a)

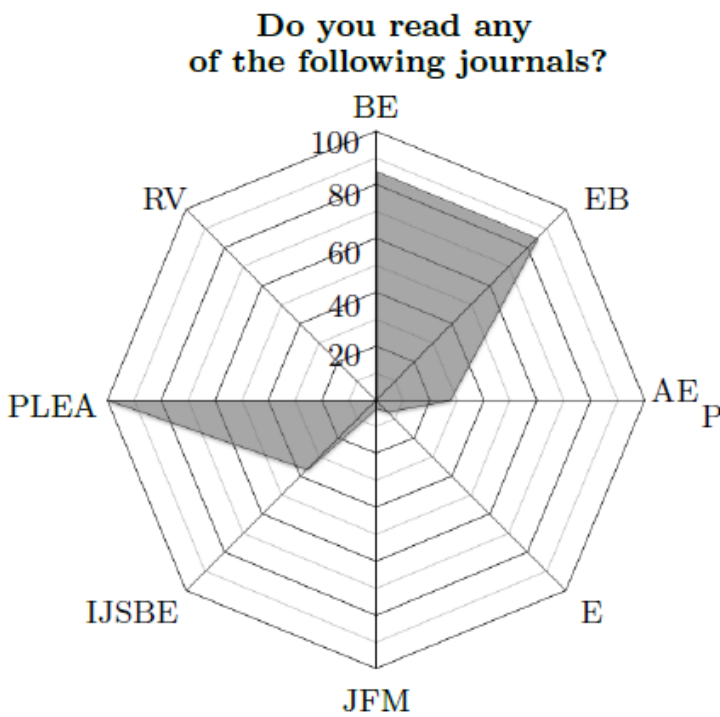

(b)

\section{Would you be interested to read} any of the following journals?

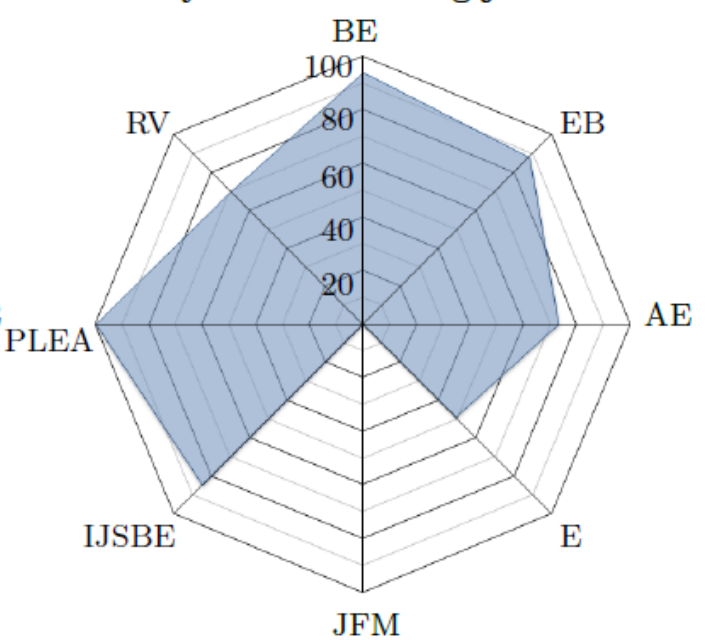

Figure 4.: Radar charts showing the percentage of students who: (a) read a particular journal; (b) are interested in reading a particular journal. Reading in a clockwise direction, the abbreviations labelled on each corner are: Building and Environment (BE), Energy and Building (EB), Applied Energy (AE), Ergonomics (E), Journal of Fluid Mechanics (JFM), International Journal of Sustainable Built Environment (IJSBE), Proceedings of Passive and Low Energy Architecture (PLEA), and Proceedings of Roomvent (RV). 
There is a unanimous preference for articles that are published in PLEA ${ }^{4}$ conference proceedings - all 33 giving this as their number one choice. This overwhelming preference may be, in part, influenced by the interdisciplinary nature of this particular conference. Other well-established conferences that cover building ventilation (e.g. Roomvent, CIBSE or $\mathrm{AIVC}^{5}$ conferences) are often of a more technical nature and geared towards attracting specialists spanning the building physics, fluid dynamics and wider ventilation communities, rather than solely specialists in one particular field of interest.

Interdisciplinary journals, in particular 'Building and Environment' and 'Energy and Buildings', are also favoured as they span a broad spectrum of applied research topics and, therefore, were deemed by the respondents as being well suited to their changing information requirements at different design stages.

Whilst the appearance of the Journal of Fluid Mechanics (JFM) may, at first sight, appear out of place on our list, it was included as this journal now holds an expansive body of information (and guidance) on natural ventilation. Indeed, advancements in our understanding and predictive capability of numerous fundamental aspects of natural ventilation, essential information for design, may be found solely therein: examples include a comprehensive model for underfloor heating (Gladstone \& Woods, 2001), the link between the thermal plumes that rise above heat sources and the stratification/airflow rates they establish in a room (Cooper \& Linden, 1996; Kaye \& Hunt, 2004, Linden et al., 1990; Shrinivas \& Hunt, 2014), the effects of assisting and opposing winds on room ventilation (Hunt \& Linden, 2001, 2005), the role played by thermal mass (Holford \& Woods, 2007), the link between the direction of airflow through openings in a façade and opening geometry/room stratification (Hunt \& Coffey, 2010), and numerous others. Although potentially of direct benefit for both enabling and enhancing ventilation design, the results of our survey reveal that this journal is not consulted, nor is it judged to be of interest to read (Figure 4). This finding is not surprising given the title of the journal itself is unlikely to lead an architect to consult it further. Moreover, with this perceived isolation from a design context, it is understandable that no direct association is made by architectural students between JFM and natural ventilation design work. Whilst a keyword search (e.g. natural ventilation, building, etc.) may retrieve individual articles from JFM, the text therein is necessarily couched in technical terminology and mathematical notation, and thus caters only to a limited readership.

\section{Students were open to seeking guidance from research academics, engineers and fellow architects.}

Our survey also explored the respondents' perception of (i) research academics with interest/expertise in low-energy building ventilation, (ii) practising architects and engineers in industry, and specifically whether they are willing to seek advice from them during the course of a natural ventilation design. Despite a few criticisms that emerged, there was, in general, an overall culture of respect towards members of each professional discipline. Their responses are illustrated graphically on a bar chart in Figure 5.

Of the three professions, support and advice from engineers was most favoured (receiving 94\% of votes for 'yes'). Engineers were perceived as 'trustworthy' and with 'expertise in dealing with technical issues which architects cannot solve alone', and as being able to provide architects with the 'exact numbers and dimensions' required in a design. On the other hand, $6 \%$ perceive engineers' guidance as 'too standardised' and that it 'lacks innovation and awareness of architectural issues'.

$70 \%$ perceived practising architects in industry as 'practical' and as practitioners who 
Would you consider seeking advice from the following individuals when designing a naturally ventilated building?

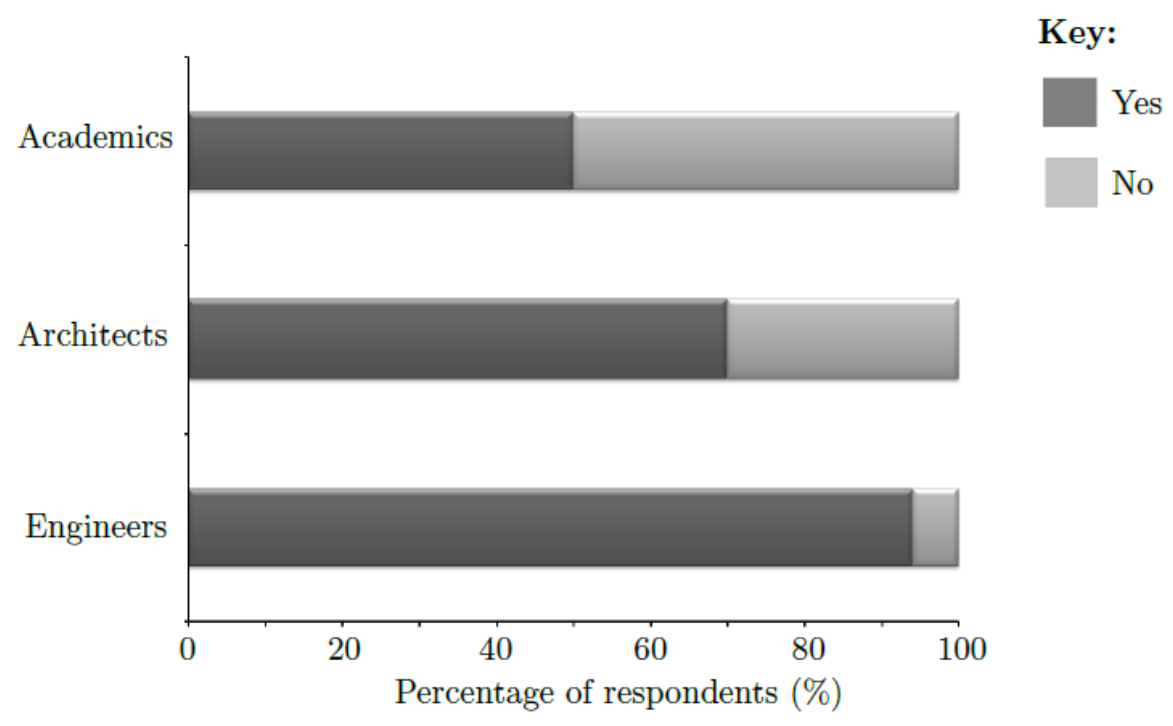

Figure 5.: Stacked bar chart showing the percentage of architectural students who would consider, or would not consider, seeking the advice of research academics in lowenergy building ventilation, practising architects and practising engineers in industry.

can offer solutions that are 'more creative' and 'outside-of-the-box' than (a perceived) 'standard approach given by engineers'. Despite the generally positive response to seeking advice from architects in industry/practice, $30 \%$ of the respondents expressed some reservation towards seeking their design advice. These respondents expressed concerns over their ideas being 'copied' by other architects, which they perceived would jeopardise their strive to create 'unique' and 'signature' building designs.

There is an equal split between students who would, and would not, consider consulting research academics for design guidance. Those who held a more positive view of academics identify them to be equipped with 'in-depth theoretical know-how' and as able to provide architects with 'trustworthy technical information'. By contrast, others identify their advice as 'too theoretical' and that they 'lack practical skills and experience in the field of architecture'.

\subsection{General (perceived) knowledge of natural ventilation in buildings and design concerns}

A series of questions was posed in the questionnaire that probed the student architects' perception of their own knowledge and understanding of natural ventilation, together with their confidence and ability to apply theoretical principles in order to perform key quantitative design calculations.

\section{Designing a naturally ventilated building was perceived to enhance the} creative skills.

All respondents expressed their aptitude toward the inclusion of natural ventilation strategies in their own building designs. There was unanimous agreement that 
designing a naturally ventilated building presents 'an even greater challenge for architects' compared to its air-conditioned counterpart, that it allows their 'creative skills to be put into practice', and gives 'architectural expression to a technical issue'.

The majority of students were confident in their ability to size and locate ventilation openings to achieve a specific airflow rate, and regarded this know-how as integral to natural ventilation design.

The stacked bar chart in Figure 6 summarises the responses regarding their perceived knowledge for sizing and locating openings to achieve (a) a specific airflow rate, (b) a comfortable indoor environment, and (c) to harness the effects of an external wind. A summary of the results is given in Table 1

\section{Do you know how to size and locate openings to achieve the following requirements?}

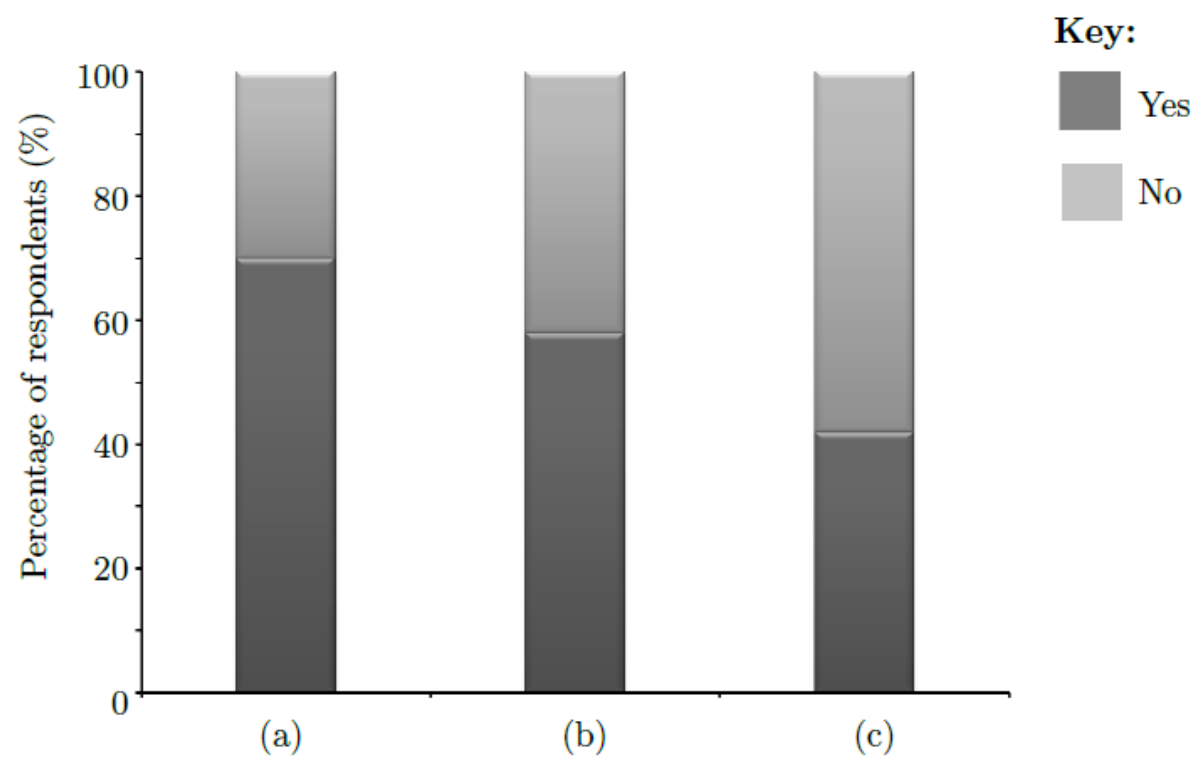

Figure 6.: Stacked bar chart showing the percentage of respondents who perceive they 'know' or 'do not know' how to size and locate openings to achieve one of the following requirements: (a) deliver a specific airflow (i.e. ventilation) rate; (b) deliver thermal comfort; and (c) harness the effects of wind.

These findings indicate that the architectural students are generally confident in their own ability to size and locate openings, and in particular, to achieve a specific (or desired) airflow rate. This is somewhat surprising to find given that determining the actual size of openings for a naturally ventilated building is a major technical challenge in design. Even for specialist ventilation engineers, sizing openings for natural ventilation presents a highly complex task; not only is there a need to ensure that vent sizes and locations result in an airflow in the direction desired but, ultimately, a complex interplay between the heat accumulated in the space, the distribution of the openings and the details of the opening geometry give rise to the airflow rate achieved (see, for example, Hunt \& Coffey (2010) ) - this all being further complicated if the building is exposed to wind.

Of note was that only five students had come across the term 'Discharge coefficient' 
Table 1.: Summary of responses regarding perceived knowledge on sizing and locating openings for natural ventilation. Entries in the first two columns give, as a percentage of the total number surveyed, those claiming to know/not know how to size and locate openings to achieve a given requirement (a), (b) or (c). Entries in the third column give the percentage of those who attach an importance to the ability to size and locate vents. The number of respondents who chose a particular option is given in parenthesis.

\begin{tabular}{lccccc}
\hline & \multicolumn{2}{c}{ Do you know how to? } & & \multicolumn{2}{c}{ Is it important? } \\
\cline { 2 - 3 } \cline { 6 - 6 } Aspect/requirement & Yes & No & & Yes & No \\
\hline (a) Specific airflow rate & $70 \%(23)$ & $30 \%(10)$ & & & \\
(b) Thermal comfort & $58 \%(19)$ & $42 \%(14)$ & & $94 \%(31)$ & $6 \%(2)$ \\
(c) Harness the wind & $42 \%(14)$ & $58 \%(19)$ & & & \\
\hline
\end{tabular}

(see 3.5 .1 and Table 2). Knowledge of (or at least an estimate of) the value for this coefficient is a key requirement for the sizing of ventilation openings (Chiu \& Etheridge, 2007; Flourentzou et al., 1998; Holford \& Hunt, 2001). As a consequence, we may deduce that the percentage of respondents who know how to size openings to attain a specific airflow rate may be somewhat below the $70 \%$ who made this claim.

Reassuringly, our results did indicate that there is a general consensus that the size and location of openings made in a façade are integral for the success of any natural ventilation design, and this know-how is of importance to architects, particularly at early design stages. The respondents reasoned that:

It is a fundamental issue for us [architects] because it affects our overall design and the thermal and psychological experiences of occupants.

Architects must be able to predict these aspects so that the best ventilation strategy can be selected to suit the form and function of the proposed building design. Without such knowledge, there is no point to provide natural ventilation in the first place.

\subsection{Representing air flows in buildings}

In building ventilation, a fundamental challenge often confronted by architects (and engineers) at an early design stage is to determine the area and location of individual openings that will provide the necessary ventilation. This is often referred to as the 'inverse problem' (Ghiaus \& Allard, 2005), as rather than calculating the airflow rate based on a given total opening area, individual opening areas are sought, which will deliver the desired airflow rate and indoor temperature. A key requirement to achieve the desired ventilation (e.g. with displacement ventilation) is to ensure that unidirectional flow - whereby exterior air enters the space through lower openings and warm interior air is discharged solely out through openings made in the façade at higher elevations - is established and maintained.

Prior to our investigation, a broad survey of the literature on natural ventilation revealed a common theme, namely, that sketches shown in the design-based literature depict 'unidirectional' flow (as illustrated in Figure 7) despite there being limited (or rather, an absence of) guidance on how to ensure this pattern of flow be achieved in practice.

While the airflow arrows shown in Figure 7 may suggest that by simply positioning vents at the upper and lower levels of a space will result in unidirectional flow, this is not guaranteed (Hunt \& Coffey, 2010). Indeed this misconception is likely to have 


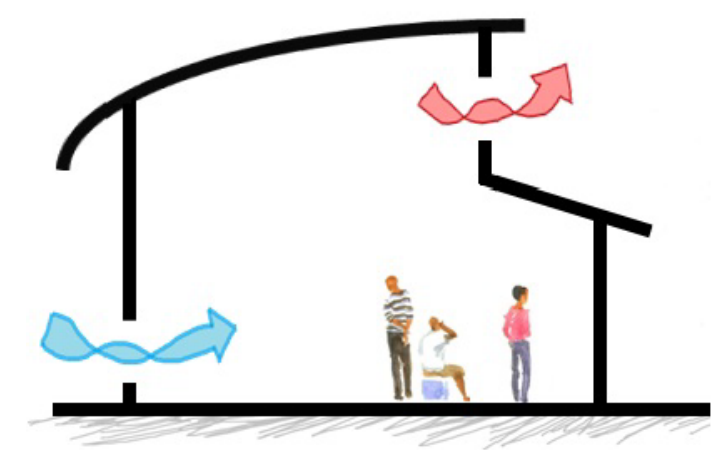

Figure 7.: An imitation of typical 'airflow arrows' at the openings of a building envelope. These airflow arrows often depict the anticipated or the desired (as opposed to the actual) direction of airflow through openings in a façade.

stemmed purely from the grounds that warm air rises and, hence, escapes out of upper openings.

Hunt \& Coffey (2010) were amongst the first to demonstrate, ${ }^{6}$ both experimentally and theoretically, that unidirectional flow (i.e. classic displacement ventilation) is not always established with openings made at the upper and lower levels in the façade. Instead of unidirectional flow, they showed that exchange flow could develop at the upper opening, particularly if the upper opening area is large relative to the area of the lower opening. The occurrence of exchange flow reduces the area of the upper opening available for discharging warm air from the space, as a proportion of this area is occupied by an inflow of cool air from the exterior. This may cause the airflow rate to reduce and for indoor temperatures to increase. Whilst these changes in ventilation may, or may not, be detrimental to the comfort of occupants, an awareness of the possibility of producing either unidirectional flow or exchange flow can only be beneficial for design.

Given the work cited above, which focusses on the transition from unidirectional to exchange flows, is published in the Journal of Fluid Mechanics (which, according to our earlier findings is not a reference of choice for architects), it was to be anticipated that the respondents may not be fully informed on how to achieve either unidirectional or exchange flow at an opening in a façade in practice. Thus, we conjectured that the respondents may have misconceptions regarding the sizing of individual openings. To test our conjecture, we wished to find out how the students expect air to flow through the upper and lower openings of a naturally ventilated space with different relative vent area configurations.

To this end, schematics were provided in the questionnaire (Q14, Appendix) showing two possible designs for a ventilated building with openings in its façade at high and low levels. Crucially, the total opening area for both designs (sum of upper and lower areas) was set to be identical. However, the apportioning of this total, between upper and lower vents, differs between the two designs - the area of the upper opening in the design shown in Figure 8(b) purposely drawn to be large compared to that shown in Figure 8(a). The students were required to indicate the anticipated/likely direction of flow through these openings. The two building envelopes are redrawn in Figure 9 with arrows superimposed to indicate the two possible solutions for the direction of airflow. Whilst, in principal, there is no correct or incorrect solution here (due to the intentionally limited information offered in the question) the primary aim was to establish whether there was an awareness of anything other than unidirectional flow. 
(a)

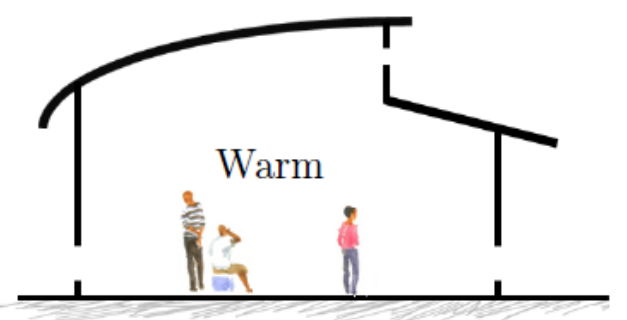

(b)

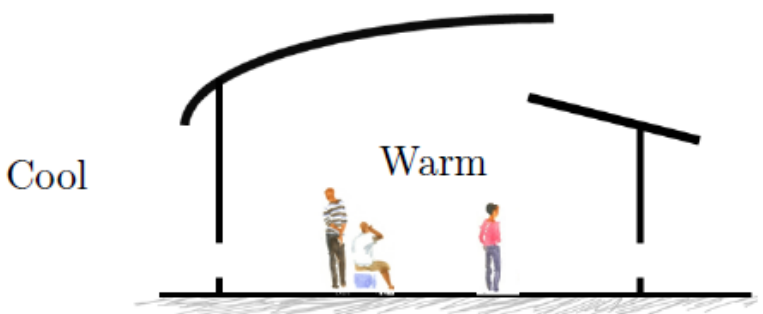

Figure 8.: Schematics of an example building envelope in elevation indicating the position and relative sizes of upper and lower vents: (a) small upper vent and (b) large upper vent. The external environment considered is uniform in temperature, cooler than the interior, and wind free. Respondents were asked to indicate on (a) and (b) the anticipated direction of airflow through each opening.

(a)

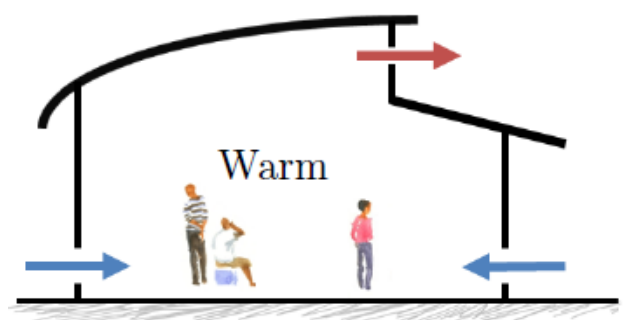

(b)

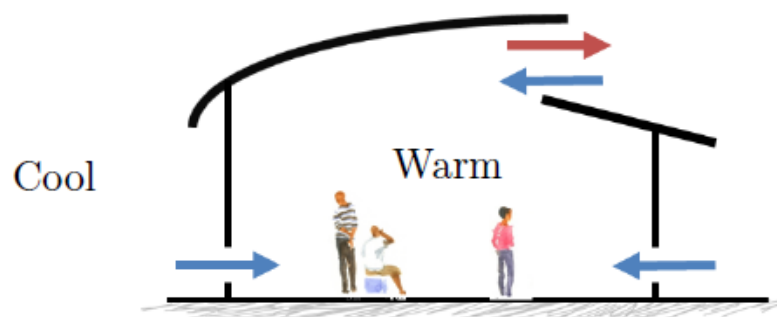

Figure 9.: Building envelopes of Figure $8(\mathrm{a}, \mathrm{b})$ with airflow arrows superimposed to indicate the likely direction of airflow through each opening in the façade. 'Outflow' arrows indicate an outflow of warm air from the interior to the exterior. 'Inflow' arrows indicate an inflow of cool air from the exterior into the interior. In (a), unidirectional (out)flow is expected through the (small) upper vent. In (b), exchange flow (i.e. simultaneous outflow and inflow) may be expected at the upper vent as it is relatively large in area compared with the lower vents.

The direction of airflow through openings made in the façade was perceived as unidirectional (i.e. in a single direction), regardless of how opening areas are apportioned between the upper and lower levels in the façade.

The respondents' sketches of the perceived direction of airflow through openings in the façade of the two designs, Figure $8(a, b)$, were grouped in terms of whether their airflow arrows indicated solely an outflow at the upper vent (i.e. they expected unidirectional flow), or whether their arrows indicated an outflow and inflow at the upper vent (i.e. exchange flow is anticipated). Any additional flow patterns that did not fit either of the two categories were grouped as 'other'. The pie charts shown in Figure 10(a,b) summarise the perceived direction of airflow through these openings.

Hunt \& Coffey (2010) showed that unidirectional flow is attainable only for a specific range of vent area configurations and not simply for all configurations with vents at low and high levels. However, despite the two different designs shown, an overwhelming $80 \%$ expected unidirectional flows to be established in each case, i.e. regardless of the 
(a) Small upper opening

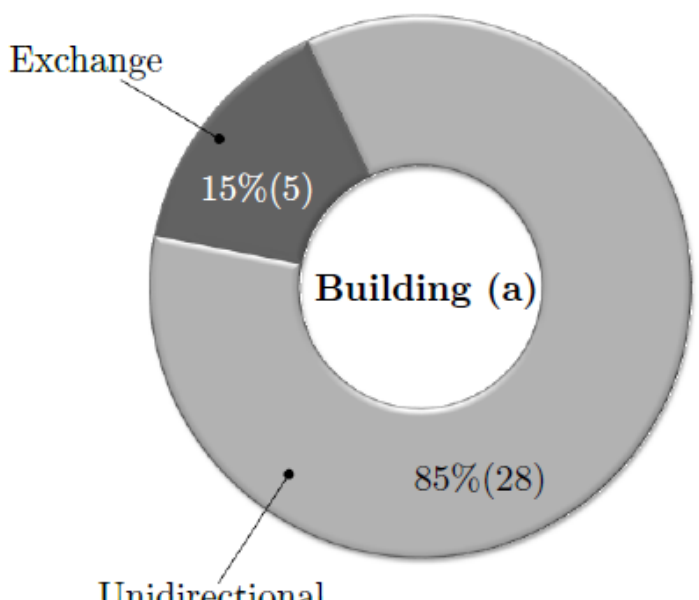

(b) Large upper opening

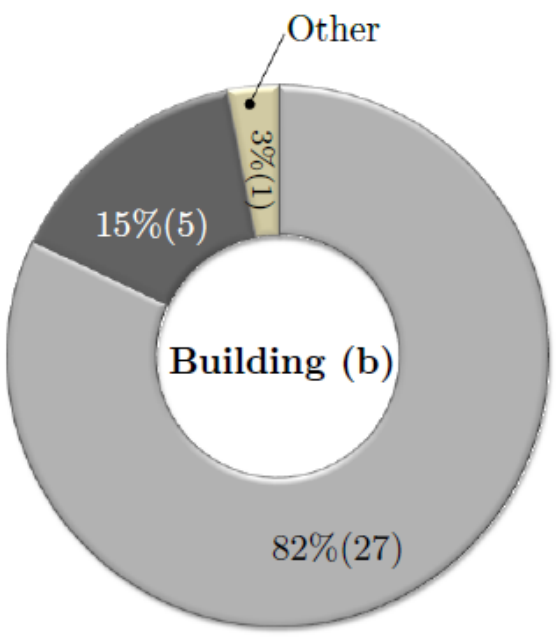

Figure 10.: The percentage of respondents expecting either unidirectional flow, exchange flow or 'other' airflow patterns through openings in the façade of building designs (a) and (b) shown in Figure 8.

relative vent area configuration. This finding is noteworthy given that $70 \%$ of the respondents perceive they know how to size ventilation openings that can achieve a specific airflow rate (see Table 1).

\subsection{Perceived barriers to the design of a naturally ventilated building}

In 1996, a European-based research project, the NatVent project, set out to identify barriers perceived by professions in the building industry (specifically architects, engineers, building owners, developers and government decision makers) which dissuade them from adopting a natural ventilation strategy in the design of office-type buildings. The results of the study, summarised by Aggerholm (1998), revealed that problems associated with the ingress of air and noise pollution in urban environments, and the lack of 'good' sources of natural ventilation knowledge were perceived as the greatest barriers. Inspired by NatVent, we wanted to determine, more than two decades on, the factors that may possibly still deter or prevent the architectural students from electing to develop a natural ventilation design.

The following six potential (or perceived) barriers to the development of a successful natural ventilation design were listed in the questionnaire:

(a) strict building standards and regulations;

(b) unpredictably and unreliability of natural ventilation to meet ventilation and comfort requirements;

(c) inner city pollution and noise;

(d) restricted design freedom;

(e) difficulty in assimilating the (vast) quantity of information on natural ventilation design; and

(f) lack of good quality natural ventilation design guidance available specifically for 
architects.

In a tick box beside (a)-(f) on the questionnaire, respondents could select either 'yes', i.e. perceived as a potential barrier, or 'no'.

\section{The greatest perceived barriers to the design of naturally ventilated build-} ings were inner city pollution and noise.

Figure 11 summarises the overall responses to the six different barriers listed above. These results show that concerns regarding inner city pollution and noise (85\% of votes), followed by stringent building regulations and standards ( $70 \%$ of votes), are perceived as the two main barriers to the implementation of natural ventilation strategies in buildings. By contrast, less than half of the respondents felt hampered, in terms of making pertinent design decisions, by what they regarded as inadequacies in the information on natural ventilation design currently available to them (or that they were aware of). Not a single respondent perceived natural ventilation design as a topic that would constrain their freedom to create aesthetically pleasing buildings.

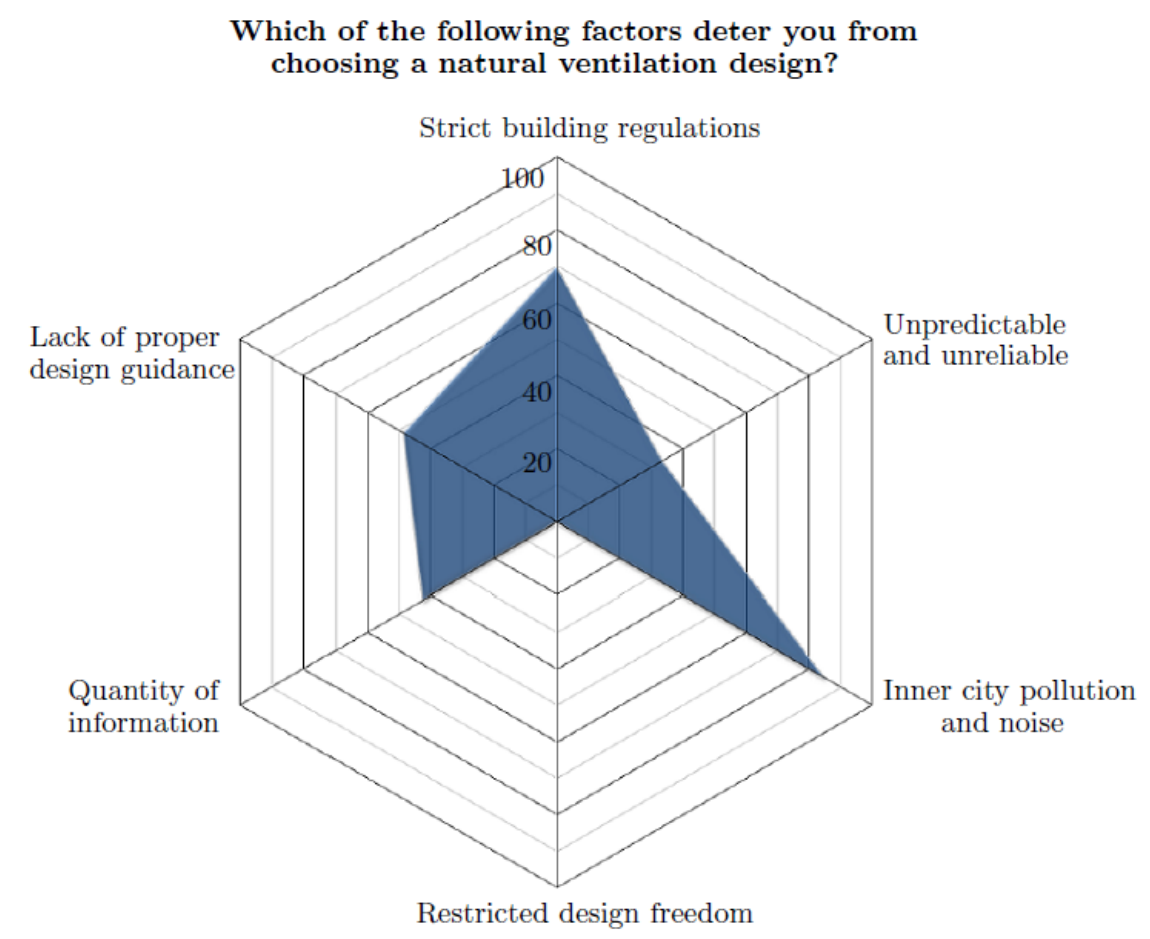

Figure 11.: Radar chart showing perceived barriers to effective natural ventilation design. The percentage awarded to each barrier represents the number of votes it received divided by the total number (33) of participants. 


\subsection{Characteristics of preferred styles and formats for the presentation of natural ventilation design information}

\subsubsection{Terminology}

Precision in scientific writing often dictates the use of technical terminology and mathematical notation. It is often difficult, if the author (i.e. technical practitioner) is deeply involved in their own subject/professional field, to realise that the most commonplace terms and ways of conveying information, widely recognised by a scientific audience, may be unfamiliar to others in different fields. This presentation style could hamper, or even prevent, the uptake and application by architects of recent (or even seasoned) research findings on natural ventilation.

Prior to the survey a list, comprising 24 terms relating to natural ventilation and aspects of its design, was devised (Table 2). These terms appear either in the designbased or science-based literature, and sometimes in both. Herein, we refer to terms appearing predominately in the scientific literature as 'technical' terminologies, and to terms most often used in design-type literature as 'architectural' terminologies. The students were asked to select, amongst the 24 terms, those they are most familiar with. ${ }^{7}$

Technical terminologies used to describe or characterise natural ventilation flows were the least familiar.

Overall responses, ranked from most familiar to least familiar, are summarised in Table 2. technical terms are highlighted in bold and architectural terms in italics. The stark distinction seen, between the familiarity with architectural and technical terminologies, broadly indicates that the majority of the architectural students are unfamiliar with the technical terminologies relating to natural ventilation airflow and design that are widespread in the scientific/engineering literature.

Of the 24 terms, 'Non-dimensional graph' proved the least familiar. Other unfamiliar terms were 'Discharge coefficient', 'Mixing flow' and 'Thermal interface', which were each selected by five respondents.

Given 'displacement flows' (ranked a lowly 18th in terms of familiarity, Table 2) are regarded by building standards and design guidelines (e.g. CIBSE AM10 (CIBSE, 2005)) as one of the most efficient methods of ventilation to expel excess heat and pollutants from within a building (compared with, for example, mixing flow or exchange flow, see also Hunt \& Kaye (2006) and Coffey \& Hunt (2007)), a somewhat surprising result was that only nine students selected the term 'Displacement flow'. In comparison, the term 'Exchange flow' received 20 ticks, again curious given that only five students expected exchange flow at the larger upper opening in the example building façade (Figure 8(b)).

Fewer students are familiar with the term 'Thermal interface' compared with 'Stratification', also surprising given that the height of the interface above the floor is a key factor in determining occupant comfort, e.g. Etheridge (2011), Fitzgerald \& Woods (2010), Gage et al. (2001), Kaye \& Hunt (2004), Linden et al. (1990), Lomas (2007).

\subsubsection{Schematics}

The majority of respondents regarded the 'box-like' representation of a naturally ventilated space as acceptable, and not at all disrespectful to the architectural practice.

Since architects, in general, are an expertly visual audience, we conjectured that the 
Table 2.: List of 24 architectural and technical terms related to natural ventilation airflows and natural ventilation design. The terms are ranked according to the number of votes each received (in parenthesis). Terms often appearing in design-type literature are highlighted in italics; those more commonly found in technical literature are in bold. Terms that are not highlighted are those that commonly appear in both technical and design-type literature.

\begin{tabular}{clc}
\hline Rank & Terminology & \% respondents \\
\hline 1 & Adaptive thermal comfort & $100 \%(33)$ \\
2 & Air changes per hour & $100 \%(33)$ \\
3 & Cooling load & $100 \%(33)$ \\
4 & Windcatcher & $100 \%(33)$ \\
5 & Cross ventilation & $94 \%(31)$ \\
6 & Solar chimney & $91 \%(30)$ \\
7 & Effective opening area & $88 \%(29)$ \\
8 & Single-sided ventilation & $85 \%(28)$ \\
9 & Buoyancy & $85 \%(28)$ \\
10 & Biomimicry & $64 \%(21)$ \\
11 & Exchange flow & $61 \%(20)$ \\
12 & Stratification & $61 \%(20)$ \\
13 & Heat flux & $55 \%(18)$ \\
14 & Draught risk & $48 \%(16)$ \\
15 & Unidirectional flow & $45 \%(15)$ \\
16 & Bidirectional flow & $39 \%(13)$ \\
17 & Pressure coefficient & $30 \%(10)$ \\
18 & Displacement flow & $27 \%(9)$ \\
19 & Neutral pressure level & $24 \%(8)$ \\
20 & Streamlines & $18 \%(6)$ \\
21 & Thermal interface & $15 \%(5)$ \\
22 & Mixing flow & $15 \%(5)$ \\
23 & Discharge coefficient & $15 \%(5)$ \\
24 & Non-dimensional graph & $0 \%(0 \%)$ \\
\hline
\end{tabular}

'box-like' depiction of a naturally ventilated space - that is, a simplified representation of a building envelope widely used in the mathematical analyses of room airflows could be perceived by architects as 'disrespectful' to the architectural practice. After all, an architect's aspiration for creating impressive and unique building designs has, in essence, been abstracted and distilled into a simple rectangular box. With an aim of our study being to assess how best to convey information on natural ventilation effectively to architects, we were mindful that the simplified schematics used as a starting point for analysing airflows in buildings would not be perceived as discrediting their craft.

We enquired in our questionnaire as to whether the 'box-like' geometry of a ventilated space (Figure 12(b)) was deemed to be representative of the sketch of a building (Figure 12(a)). We then asked whether they perceive the 'box' (Figure 12(b)) to be disrespectful to their practice. The bar chart in Figure 13 summarises the responses.

Our findings show that the respondents do not entirely reject the 'box-like' representation of a naturally ventilated space; $82 \%$ consider it to be 'representative', $58 \%$ of whom perceive it as 'respectful' (unfortunately, although invited, none of the students provided a reasoning for their choice). On the other hand, $18 \%$ rejected the 'box', $15 \%$ of whom consider it as 'disrespectful'. Two students commented that:

It [box-like space] is too abstract, I don't understand it.

It does not take into consideration the architectural interpretation of design strategies.

The students were then asked to resketch the 'box' in a form they saw fit. The major- 
(a)

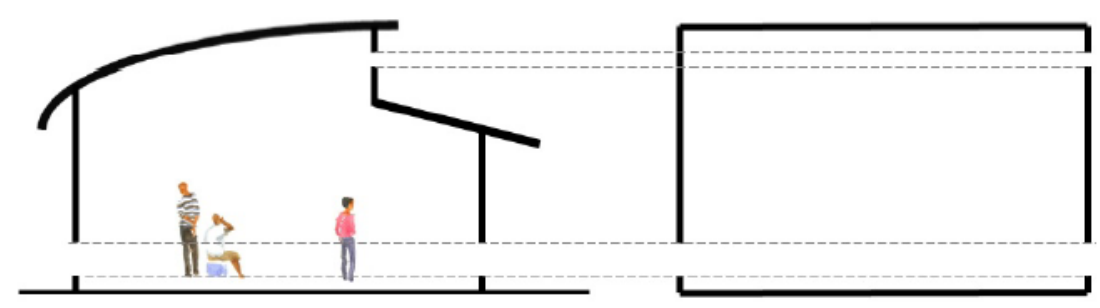

Figure 12.: Two line drawings of a ventilated space in elevation with upper and lower openings. The schematic in (b) is a simplified representation of the sketch in (a). This form of simplification is typical of those used in scholarly articles which develop simplified mathematical models (and analogous experimental models) of airflow behaviour and stratification in naturally ventilated spaces, see Linden (1999) for a review. Construction lines linking (a) and (b) are drawn to indicate that the vents in both schematics are located at the same heights.

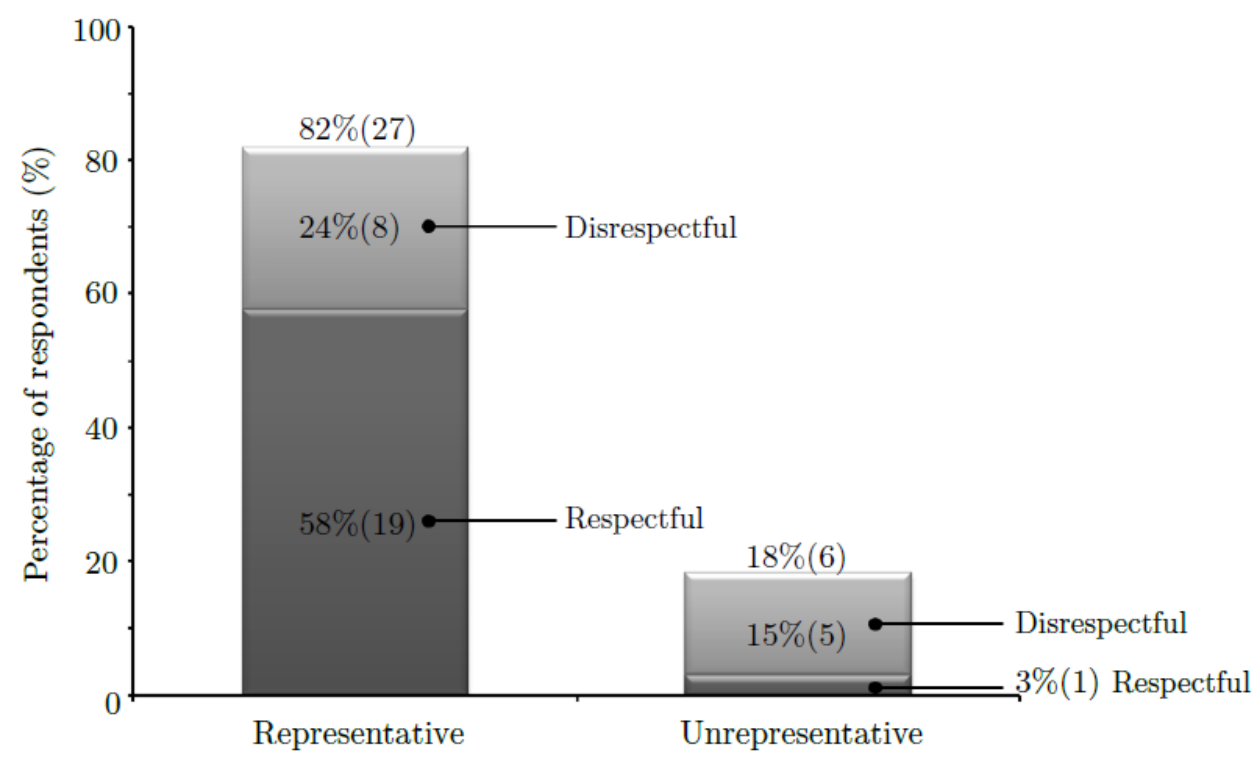

Figure 13.: Stacked bar chart showing the percentage of respondents who regard the 'box-like' geometry in Figure 12(b) to be representative (left bar) or unrepresentative (right bar) of the building façade sketched in Figure 12(a). Each bar is further divided into those who regarded the box as 'respectful' and as 'disrespectful'. The number of respondents who selected a particular option is given in parenthesis.

ity included a 'ground line' to indicate the drawing is in elevation. They also included a sketch of an occupant within the space as a 'visual scale' that relates the height of a space to the height of an average person. Additionally, they included a slanted roof in their sketch to more closely represent the roof of the building in Figure 12(a). While there is no one ubiquitous typographical style which would be pleasing to every architect, the value of including the ground line, slanted roof and visual scale in a sketch was shared amongst the respondents. Drawing from some of their comments 
and suggestions, Figure 14 illustrates, what may be regarded as, characteristics of an 'ideal ventilated box schematic' as seen through the eyes of the architect.

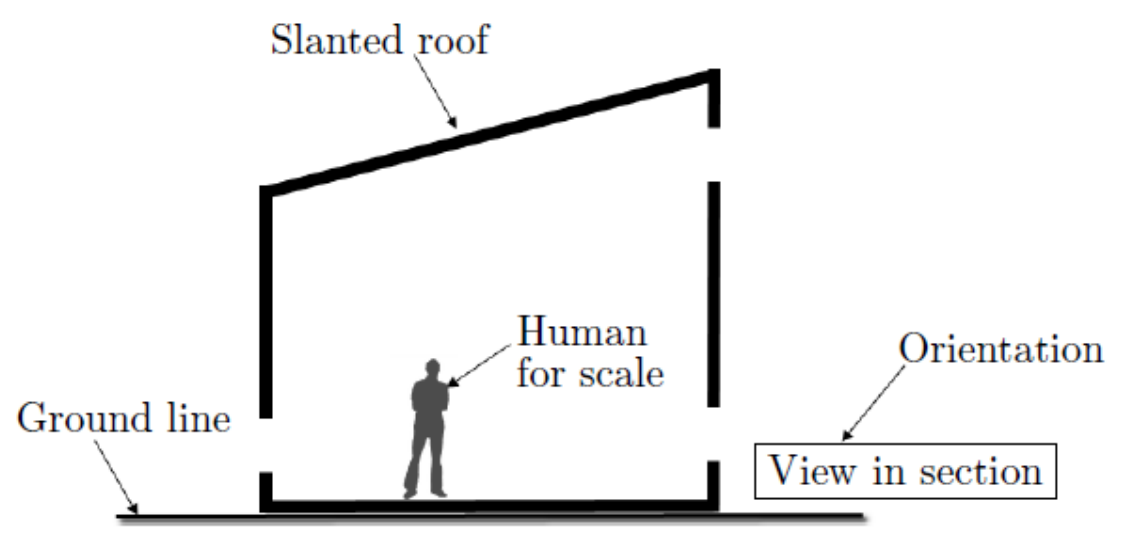

Figure 14.: Illustration of an 'ideal ventilated box schematic', which may be regarded as a 'architecturally friendly' schematic of a simplified building envelope in comparison to the 'box-like' depiction in Figure 12(b).

\subsubsection{Desirable qualities for future natural ventilation design guides}

Our investigation revealed that there are some favoured ways of presenting information that are shared by the architectural students. Herein, we summarise the responses to their preferred format, style and level of detail for a future natural ventilation design guide perceived as congenial to their practice.

Desired format of a future design guide: published as a stand alone book. The radar chart in Figure 15 indicates the responses to five different formats: a series of research papers, a stand alone (physical) book, RIBA $^{8}$ books, architectural digests, and 'other' (e.g. websites).

These findings indicate that over $90 \%$ would prefer a design guide to be published as a stand alone book, as opposed to alternative formats such as digests and journal articles (PDF documents) that are readily accessible online.

\section{Preferred level of detail for design guide: lengthy and detailed.}

$60 \%$ were in favour of a lengthy and detailed design guide on natural ventilation. Those who included a reasoning behind their choice wrote:

The longer the better. I like to understand what is behind the guide in detail.

A better understanding of principles allows for more creative solutions in design.

As architects, we need to justify for our design choices (to a client) and why we chose a particular ventilation strategy. It is better to know the details behind the strategy to have evidence to back us up.

We [architects] want to learn, and not just blindly input data into computer simulation programmes.

In contrast, $40 \%$ would prefer a short, brief and concise guide consisting of highly focussed (i.e. distilled) information on natural ventilation design. In particular, these 


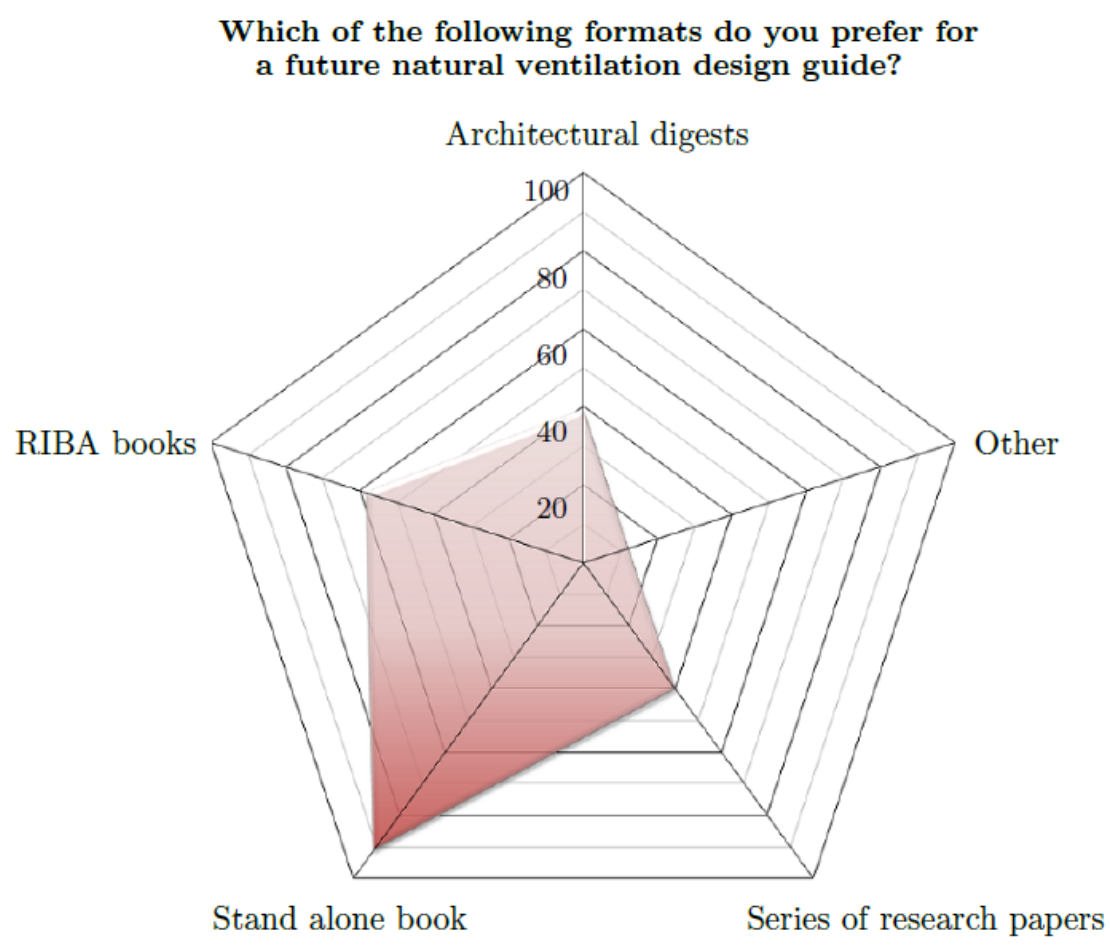

Figure 15.: Radar chart showing the preferred formats for a natural ventilation design guide. Percentages represent the number of votes received divided by the total number (33) of participants.

respondents emphasised aspects of brevity and clarity as important since:

Short design guides are easier and more practical to use and apply in a design.

They are quicker for me to read and to retrieve the right information I need. Long guides are too time-consuming.

Desired presentation style for design guide: visual information (such as diagrams, checklists, charts) with limited use of mathematical equations. Opinions were sought on the desired style(s) of presentation of information for a future natural ventilation design guide. They could choose from a selection of styles consisting of: diagrams and schematics, charts and graphs, checklists, mathematical equations, or a combination of two or more styles. A summary of the responses is illustrated in Figure 16 .

Figure [16 reveals that, above all others, the greatest preference is for pictorial presentation styles. Specifically, in excess of $60 \%$ would prefer a design guide to consist of a variety of diagrams, schematics, checklists charts (and possibly equations); while $30 \%$ would prefer the guide to consist predominately of diagrams and schematics only. A few respondents added additional comments, giving the reasons behind their choice:

Use of imagery and diagrams allows me to understand concepts better, which is particularly important at the early stage of design.

Checklists help me remember the necessary information related to design.

Less than $10 \%$ requested mathematical equations, and unsurprisingly, none of the 
Which of the following presentation styles do you prefer for a future natural ventilation design guide?

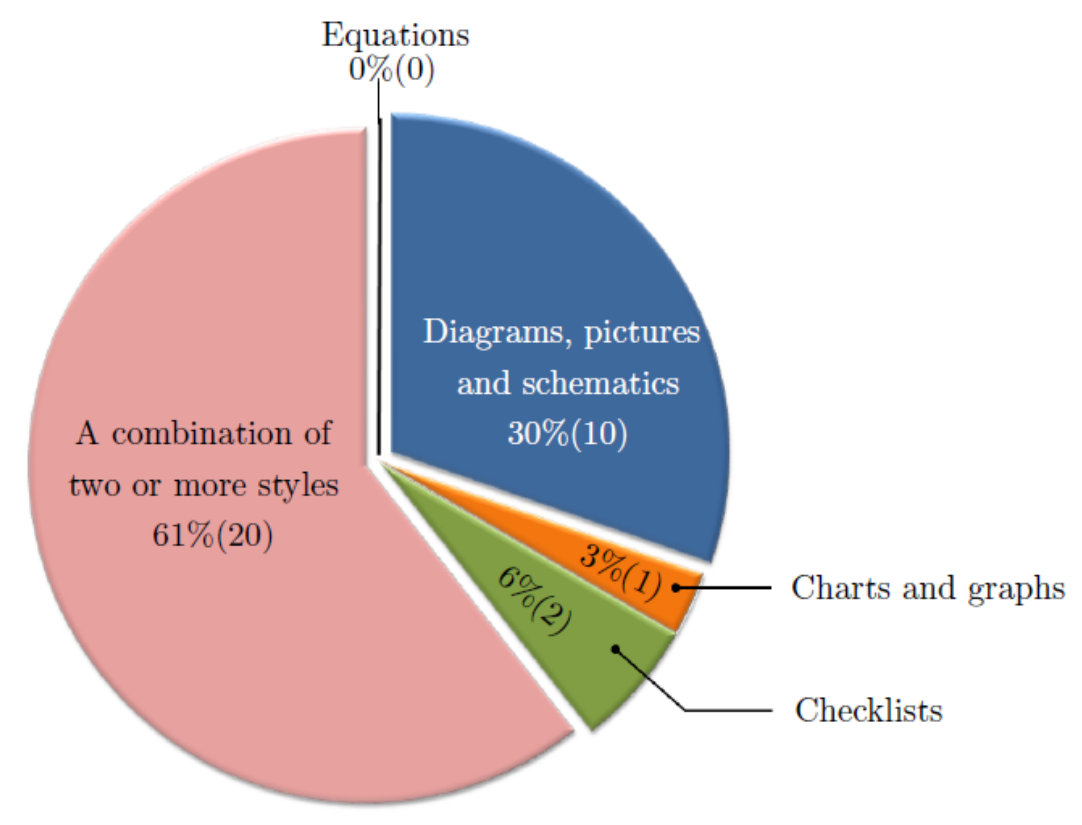

Figure 16.: Pie chart illustrating the preferred presentation styles of a design guide for natural ventilation. The number who selected a particular option is given in parenthesis.

students desired a design guide that consists solely of equations and is devoid of visual material. They commented that:

Too much theory and math equations only confuse me.

If I can't understand it, I can't use it. Physical concepts should be explained rather than using just formulae.

In our opinion, this particular finding does not suggest that the majority of respondents are reluctant to use mathematical equations, but rather that the majority prefer to understand the information they have at hand visually, particularly when trying to grasp or apply a new concept for the first time.

At the end of the questionnaire, participants were invited to offer additional suggestions for ways of enhancing the use of natural ventilation strategies in buildings by architects. The following is a synopsis of their opinions ${ }^{9}$ in which a need was identified for:

- more user-friendly computer-aided design tools; tools specifically for prediction of indoor climate (e.g. temperature and comfort) and climate response to changes made during design, and for enabling rapid demonstrations to clients and other architects in design meetings;

- design guidelines and guides that make greater use of rules-of-thumb. These rulesof-thumb should enable certain ventilation principals (no examples given) to be recalled quickly;

- greater access to case studies of precedent naturally ventilated buildings. These case studies should provide architects with a 'proof of concept' and a broader 
'guidance to possible design options'; and

- greater awareness and public perception of the benefits of natural ventilation. It was stated that 'occupants and architects should not view this [natural ventilation] as a step backwards, but a step forward in making a difference to our environment.'

\section{General recommendations and dissemination checklist}

The results that have emerged from this study may offer a few pointers for technical practitioners and course developers when next communicating to an architectural audience. These pointers are summarised in the form of a 'dissemination' checklist in Table 3.

As a general disclaimer, the checklist offers suggestions, rather than a set of requirements, which technical practitioners may consider, or refer to, when tailoring their work to be read by architects. Although these suggestions may appear, at first sight, self explanatory or obvious, our findings herein would indicate that there is considerable scope to improve knowledge transfer, and as such, the checklist may prove valuable. Evidently, choices in presentation style have a significant bearing on whether work is read, appreciated and comprehended. Crucially, to enhance the uptake of research findings, it is essential that technical practitioners be aware of the conventions and terminologies that are particular to architects, as well as architects' unique means of assimilating information. For these reasons, we draw attention to the salient, likely taken-for-granted recommendations in Table 3.

\section{Discussion and Conclusions}

Our survey was conducted on a group of MA/MSc/MArch student architects to explore their current information needs regarding the design of naturally ventilated buildings. We designed the survey to be a 'sounding board' for architects' opinions; their opinions were sought on a range of natural ventilation specific matters, including on their vision for presenting technically-orientated information in a style congenial to their interests and practice. Whilst our findings cannot be regarded as representative of the viewpoints of all architects in general, they are a snapshot of the views of a small sample of talented young architects with interests in the field of sustainable building design and with some experience of life in an architectural practice/setting. Those surveyed are likely to be practising architects of the future and, as such, we regard their views as important.

The key results that emerge from our survey are as follows. Broadly, the respondents prefer to use familiar resources for early stage design guidance, specifically case studies of exemplar buildings, CIBSE guides and articles published in PLEA conference proceedings. They regard these resources as providing immediately applicable information in support of their problem-solving at the early stages of a natural ventilation design. A 'stand alone' book (physical, rather than electronic) was the most preferred form for future architect-specific design guidance, wherein it was recommended that case studies of exemplar naturally ventilated buildings be included as qualitative means of 'proof of design' and 'verification'. It was also recommended that design guidance be written in a lengthy and descriptive format with additional tailored short summaries that allow for quick retrieval of key facts and concepts. In terms of style, the preference was overwhelmingly for visual presentation - specifically using scaled drawings 
Table 3.: 'Dissemination' checklist with suggestions for enhancing the uptake of technical information on natural ventilation design by architects.

\begin{tabular}{|c|c|}
\hline Recommendation & Key points \\
\hline Simplify technical terminologies & $\begin{array}{l}\text { - Use 'architectural' or layman vocabulary where possible } \\
\text { - Avoid the use of 'technically-focussed' terminology and } \\
\text { mathematical notation that are unfamiliar to architects }\end{array}$ \\
\hline $\begin{array}{l}\text { Make title and content relevant to } \\
\text { architects }\end{array}$ & $\begin{array}{l}\text { - Place the title and content of the research within a design } \\
\text { context that is directly relevant to architects } \\
\text { - Translate technical information into an appropriate format } \\
\text { and style that is suited for a particular stage in a natural ven- } \\
\text { tilation design process. For example, the use of design charts } \\
\text { and simple schematics to provide straightforward guidance at } \\
\text { the early stage of a natural ventilation design }\end{array}$ \\
\hline Include tailored short summaries & $\begin{array}{l}\text { - Include a concise summary of key facts and concepts that is } \\
\text { straight to the point } \\
\text { - Present a summary, or summaries, in which key informa- } \\
\text { tion can be quickly grasped and its relevance to the design } \\
\text { highlighted }\end{array}$ \\
\hline $\begin{array}{l}\text { Present information predomi- } \\
\text { nately through visual means }\end{array}$ & $\begin{array}{l}\text { - Use scaled drawings and illustrations that are familiar to } \\
\text { architects. For example, include a human for scale and ground } \\
\text { line in schematics of building forms } \\
\text { - Design charts and checklists are also a favourable means of } \\
\text { providing information that is immediate, intuitive and easily } \\
\text { applicable in design }\end{array}$ \\
\hline $\begin{array}{l}\text { Provide evidence-based reassur- } \\
\text { ance }\end{array}$ & $\begin{array}{l}\text { - Provide architects with concrete facts and examples that } \\
\text { reassure them to apply (and how to apply) the results. For } \\
\text { example, use case studies of naturally ventilated buildings that } \\
\text { are approved and recognised by architects }\end{array}$ \\
\hline $\begin{array}{l}\text { Present information so that it } \\
\text { can be easily remembered and re- } \\
\text { called }\end{array}$ & $\begin{array}{l}\text { - Assist architects in their 'memory retrieval' of information. } \\
\text { For example, the use of mnemonics such as aide-mémoires (e.g. } \\
\text { the 'ventilation triangle' proposed by Hunt \& Linden }(1999)) \\
\text { can generate information that is immediate, easily compre- } \\
\text { hended and recalled }\end{array}$ \\
\hline $\begin{array}{l}\text { Publish in journals which archi- } \\
\text { tects recognise and value }\end{array}$ & $\begin{array}{l}\text { - Publish work in journals which architects are accustomed to } \\
\text { reading/consulting and are, therefore, regarded as trustworthy } \\
\text { and accessible } \\
\text { - Specifically, publish work in interdisciplinary journals such } \\
\text { as, 'Building and Environment', 'Energy and Buildings' and } \\
\text { 'Architectural Science Review' }\end{array}$ \\
\hline
\end{tabular}

and familiar architectural conventions. For example, simple schematics of a naturally ventilated building envelope should include a 'human' and a 'ground line' to indicate, qualitatively, scale and orientation.

Overall, this study makes important practical contributions by identifying a number of factors that currently affect, detrimentally, the transfer and impact of technical information from engineering/scientific spheres to end users within the architectural community. Crucially, there is a need to position the key design-relevant information in the hands of the end user and this survey has (i) served to expose many avenues in which knowledge transfer can be improved and (ii) prompted and guided the specific recommendations made herein regarding the style and format for guidance that will likely ensure improved uptake.

The narrow focus of this study, however, may be of questionable value since it is based on two premises. First, it is assumed that if the information is written in ideal 'exemplary' formats with the 'correct' visual characteristics, architects can access it and, thus, will choose to apply it to their own building designs. Second, it is assumed 
that if the architects do apply it, their designs would consequentially improve. While necessary, 'good' presentation per se is not sufficient to overcome existing barriers to the uptake of technical information by architects. There may be other forces at work beyond aspects of 'aesthetics' alone which this study has not explored. The choices architects make and how they assimilate information are also influenced by their predispositions, which in turn, are likely to be grounded in a deeply held set of beliefs instilled by their architectural training and experience. These beliefs can have an overriding effect on an architect's perceived value of the information they have at hand. Viewed from this perspective, the presentation of information can be treated not as an isolated factor, but simply as one factor - inter alia - affecting the impact of technical research within the architectural community. It is, perhaps, to these often unexpressed and less 'quantifiable' factors that attention needs to be drawn if further attempts are to be made to bridge communication barriers between both professional fields.

\section{Notes}

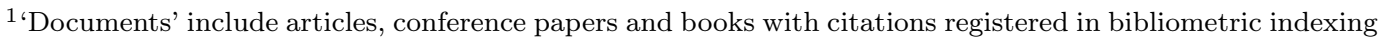
databases. At the time of writing, the source database, Scopus, is one of the largest abstract and citation databases of peer-reviewed literature.

${ }^{2}$ The AA requires students to take their fourth year out for practical training as part of the undergraduate course Architectural Association Inc. 2017). However, not all students we surveyed did their undergraduate degree at the AA, some having studied abroad prior to starting at the AA.

${ }^{3}$ The Architects' Journal provides up-to-date architecture news related to building projects within the UK and internationally, and a platform for opinions on design- and construction-related matters.

${ }^{4}$ Passive and Low Energy Architecture (PLEA) is an 'autonomous, non-profit network of individuals sharing expertise in the arts, sciences, planning and design of the built environment'. Founded in 1981, PLEA holds annual international conferences, workshops and exhibitions, and seeks to promote interdisciplinary discussions and debate on the learnings, opportunities and challenges in passive, low-energy architecture (PLEA 2015).

${ }^{5} \mathrm{AIVC}$ is the acronym for Air Infiltration and Ventilation Centre.

${ }^{6}$ They performed an extensive programme of small-scale experiments using the 'salt-bath technique' to investigate the behaviour of heat and airflow through a naturally ventilated space with upper and lower openings. They observed that four different flow patterns are possible, each exhibiting characteristics of displacement and/or mixing flows. In particular, they showed that each flow pattern (including classic displacement ventilation) is sensitive to the way in which the total opening area is apportioned between the upper and lower levels, and crucially that unidirectional flow is attainable only for a subset of opening area configurations.

${ }^{7}$ The validity of the response is based on the premise that the respondent understood the meaning of the terms listed. Naturally, respondents could have deemed a particular term as 'familiar', having come across it in the open literature, without necessarily understanding the true meaning.

${ }^{8}$ RIBA is the acronym for the Royal Institute of British Architects.

${ }^{9} \mathrm{~A}$ total of five students provided this additional commentary.
}

\section{Acknowledgments}

G.R. Hunt and R. Baeumle gratefully acknowledge the financial support of the Engineering and Physical Sciences Research Council and Cambridge University Engineering Department. We are grateful to Dr Simos Yannas for allowing us to conduct our survey at the Architectural Association School of Architecture, and the MA/MSc/MArch students who took part and provided us with invaluable feedback.

\section{Disclosure statement}

No potential conflict of interest was reported by the authors. 


\section{Funding}

Engineering and Physical Sciences Research Council; Department of Engineering, University of Cambridge.

\section{Notes on contributors}

Recha Baeumle is a $\mathrm{PhD}$ student in environmental fluid mechanics at The University of Cambridge, with particular interests in low-energy building ventilation. As an undergraduate, Recha studied Civil and Environmental Engineering at Imperial College London, UK, before commencing her doctoral research, under the supervision of Gary R. Hunt, at the Department of Engineering. The scope of her research is aimed at developing a framework for conveying the complex fluid dynamics associated with the movement of air and heat through naturally ventilated buildings into practical design guidance that meets the needs of the modern design community.

Gary R. Hunt is a Professor of Fluid Mechanics in Cambridge University's Engineering Department.

\section{References}

Adler, E.S., \& Clark, R. (2014). An Invitation to Social Research: How It's Done. Stamford, CT: Cengage Learning.

Aggerholm, S. (1998). Perceived Barriers to Natural Ventilation Design of Office Buildings NatVent - Overcoming technical barriers to low-energy natural ventilation in office type buildings in moderate and cold climates. Watford, UK: Building Research Establishment.

Architectural Association Inc. (2017). Professional Practice Studies. [Online]. Retrieved from: http://www.aaschool.ac.uk/STUDY/UNDERGRADUATE/?name=comppp.

ASHRAE (2010). Standard 55-2010: Thermal environmental conditions for human occupancy. Atlanta, GA: American Society of Heating, Refrigerating and Air-conditioning Engineers, Inc.

Baker, N., \& Steemers, K. (2000). Energy and Environment in Architecture: A Technical Design Guide. London, UK: E \& FN Spon.

Birt, B., \& Newsham, G.R. (2009). Post-occupancy evaluation of energy and indoor environment quality in green buildings: a review. Ottawa: Institute for Research in Construction. National Research Council of Canada, Report NRCC-51211.

Chiu, Y-H., \& Etheridge, D.W. (2007). External flow effects on the discharge coefficients of two types of ventilation opening. Journal of Wind Engineering and Industrial Aerodynamics, 95(4), 225-252.

CIBSE (2005). Applications Manual AM10: Natural ventilation in non-domestic buildings. London, UK: The Chartered Institution of Building Services Engineers.

Coffey, C.J., \& Hunt, G.R. (2007). Ventilation effectiveness measures based on heat removal: 
Part 2. Application to natural ventilation flows. Building and Environment, 42(6), 22492262.

Cooper, P., \& Linden, P.F. (1996). Natural ventilation of an enclosure containing two buoyancy sources. Journal of Fluid Mechanics, 311, 153-176.

Ellis, M.W., \& Mathews, E.H. (2001). A new simplified thermal design tool for architects. Building and Environment, 36(9), 1009-1021.

Etheridge, D.W. (2011). Natural ventilation of buildings: theory, measurement and design. Hoboken, USA: John Wiley \& Sons Ltd.

Fitzgerald, S.D., \& Woods, A.W. (2010). Transient natural ventilation of a space with localised heating. Building and Environment, 45(12), 2778-2789.

Flourentzou, F., Van der Maas, J., \& Roulet, C.-A. (1998). Natural ventilation for passive cooling: measurement of discharge coefficients. Energy and Buildings, 27(3), 283-292.

Gage, S.A., Hunt, G.R., \& Linden, P.F. (2001). Top down ventilation and cooling. Journal of Architectural and Planning Research, 18(4), 286-301.

Ghiaus, C., \& Allard, F. (2005). Natural ventilation in the urban environment: assessment and design. London, UK: Earthscan.

Gladstone, C., \& Woods, A.W. (2001). On buoyancy-driven natural ventilation of a room with a heated floor. Journal of Fluid Mechanics, 441, 293-314.

Hinrichs, J.R., \& Gatewood, R.D. (1967). Differences in opinion-survey response patterns as a function of different methods of survey administration. Journal of Applied Psychology, $51(6), 497-502$.

Holford, J.M., \& Hunt, G.R. (2001). The dependence of the discharge coefficient on density contrast - experimental measurements. In B. Dally (ed.), Proceedings of the 14th Australasian Fluid Mechanics Conference (pp. 123-126). Adelaide, SA Australia: Adelaide University.

Holford, J.M., \& Woods, A.W. (2007). On the thermal buffering of naturally ventilated buildings through internal thermal mass. Journal of Fluid Mechanics, 580, 3-29.

Hunt, G.R., \& Coffey, C.J. (2010). Emptying boxes - classifying transient natural ventilation flows. Journal of Fluid Mechanics, 646, 137-168.

Hunt, G.R., \& Kaye, N.B. (2006). Pollutant flushing with natural displacement ventilation. Building and Environment, 41(9), 1190-1197.

Hunt, G.R., \& Linden, P.F. (1999). The fluid mechanics of natural ventilation - displacement ventilation by buoyancy-driven flows assisted by wind. Building and Environment, 34(6), $707-720$.

Hunt, G.R., \& Linden, P.F. (2001). Steady-state flows in an enclosure ventilated by buoyancy forces assisted by wind. Journal of Fluid Mechanics, 426, 335-386.

Hunt, G.R., \& Linden, P.F. (2005). Displacement and mixing ventilation driven by opposing wind and buoyancy. Journal of Fluid Mechanics, 527, 27-55. 
Jones, B.M., Cook, M.J., Fitzgerald, S.D., \& Iddon, C.R. (2016). A review of ventilation opening area terminology. Energy and Buildings, 118, 249-258.

Kaye, N.B., \& Hunt, G.R. (2004). Time-dependent flows in an emptying filling box. Journal of Fluid Mechanics, 520, 135-156.

Krausse, B., Cook, M.J., \& Lomas, K. (2007). Environmental performance of a naturally ventilated city centre library. Energy and Buildings, 39(7), 792-801.

Linden, P.F. (1999). The fluid mechanics of natural ventilation. Annual Review of Fluid Mechanics, 31(1), 201-238.

Linden, P.F., Lane-Serff, G.F., \& Smeed, D.A. (1990). Emptying filling boxes: the fluid mechanics of natural ventilation. Journal of Fluid Mechanics, 212, 309-335.

Lomas, K.J. (2007). Architectural design of an advanced naturally ventilated building form. Energy and Buildings, 39(2), 166-181.

PLEA (2015). About PLEA. [Online]. Retrieved from: http://www.plea2015.it/about_plea/.

Scopus (2017). About Scopus. [Online]. Retrieved from: www.info.scopus.com/about.

Shrinivas, A.B., \& Hunt, G.R. (2014). Transient ventilation dynamics induced by heat sources of unequal strength. Journal of Fluid Mechanics, 738, 34-64.

Wood, D.S. (2003). A comparison of group-administered and mail-administered surveys of Alaskan village public safety officers. Policing: An International Journal of Police Strategies \& Management, 26(2), 329-340.

For reference, herein we present the 25 questions that were asked in our questionnaire.

\section{Questionnaire for architects on natural ventilation}

Dear Colleague,

Please use this questionnaire to provide constructive feedback that will help us understand the needs of the architectural community in designing naturally ventilated buildings. Your feedback will offer valuable insight to improve our methods of conveying the physics of airflows in naturally buildings to architects. Thank you for your help.

\section{Theme 1: Personal academic background}

1. Do you have A-level or equivalent in
a. Mathematics
$\square$ Yes $\square$ No
b. Physics
$\square$ Yes $\square$ No
c. Science (Chemistry or Biology) $\square$ Yes $\square$ No
d. General Studies
$\square$ Yes $\square$ No 
2. Do you have a higher qualification than A-level in
a. Mathematics
$\square$ Yes $\square$ No
b. Physics
$\square$ Yes $\square$ No
c. Science (Chemistry or Biology) $\square$ Yes $\square$ No
d. Engineering
$\square$ Yes $\square$ No

Theme 2: Preferred types of resource for natural ventilation design guidance

3. Which of the following journal papers and conference proceedings have you read or are interested in reading?

a. Building and Environment

Have read $\quad \square$ Yes $\square$ No

Interested to read $\quad \square$ Yes $\square$ No

b. Energy and Buildings

Have read $\quad \square$ Yes $\square$ No

Interested to read $\square$ Yes $\square$ No

c. Applied Energy

Have read $\quad \square$ Yes $\square$ No

Interested to read $\square$ Yes $\square$ No

d. Journal of Fluid Mechanics

Have read $\quad \square$ Yes $\square$ No

Interested to read $\square$ Yes $\square$ No

e. Ergonomics

Have read $\quad \square$ Yes $\square$ No

Interested to read $\quad \square$ Yes $\square$ No

f. International Journal of Sustainable Built Environment

Have read $\quad \square$ Yes $\square$ No

Interested to read $\square$ Yes $\square$ No

g. Proceedings of PLEA

Have read $\quad \square$ Yes $\square$ No

Interested to read $\square$ Yes $\square$ No

h. Proceedings of Roomvent

Have read $\quad \square$ Yes $\square$ No

Interested to read $\quad \square$ Yes $\square$ No 
4. If you were designing a naturally ventilated building, which of the following sources of information would you use as reference for design guidance? (Tick all that apply)

$\square$ Design codes and building standards

State type/name:

$\square$ Previous experience and personal expectation

Case studies of already built designs

$\square$ Scientific journals

State type/name:

$\square$ Architectural journals

State type/name:

$\square$ Other, e.g. conference proceedings, websites

State type/name:

5. Would you also consider seeking advice from the following individuals when designing a naturally ventilated building?

a. Expert ventilation engineers

$\square$ Yes $\square$ No

State your reason:

b. Research academics in low-energy building ventilation

$\square$ Yes $\square$ No

State your reason:

c. Practising architects in industry

$\square$ Yes $\square$ No

State your reason:

Theme 3: Understanding of natural ventilation

6. How do you perceive your own knowledge of designing naturally ventilated buildings?

$\square$ None $\square$ Some Thorough

7. Have you read articles on the subject of natural ventilation?

$\square$ Yes $\square$ No

If yes, how many?

$\square 1-2 \quad \square 3-5 \quad \square 6+$

Where did you find these articles?

8. Have you been to any technical seminars, conferences and/or lectures on the subject of natural ventilation in buildings?

$\square$ Yes $\square$ No

If yes, how many?

$\square 1-2 \quad \square 3-5 \quad \square 6+$ 
9. Are you familiar with the following terms? (Tick all that apply)
$\square$ Adaptive thermal comfort
Air changes per hour
Heat flux
Bidirectional flow
Mixing flow
Biomimicry
Buoyancy
Cooling load
Neutral pressure level
Cross ventilation
$\square$ Discharge coefficient
Non-dimensional graph
Pressure coefficient
Single-sided ventilation
Stratification
Streamlines
Displacement flow
Solar chimney
Draught risk
Thermal interface
Effective opening area
Unidirectional flow
Exchange flow
Windcatcher

\section{Theme 4: Natural ventilation design concerns}

10. Would you consider designing a building using natural ventilation?

$\square$ Yes $\square$ No

State your reason:

11. Would you consider natural ventilation strategies to be effective for providing indoor comfort during the summer?

$\square$ Yes $\square$ No

State your reason:

12. Do you know how to size and locate openings to achieve
a. Ventilation flow rate you want $\quad \square$ Yes $\square$ No
b. Comfortable airflow without draught $\square$ Yes $\square$ No
c. Wind-assisted flow rate $\quad \square$ Yes $\square$ No

13. As an architect, do you think it is important to answer 'YES' to $a, b$, and $c$ in question 12 ?

$\square$ Yes $\square$ No

State your reason:

Theme 5: Sketching airflow paths

14. Figure 1 and Figure 2 are two sketches of almost identical buildings (see below). They each have one high-level vent and two low-level vents placed in the building envelope. The total vent area for both buildings (sum of the upper and lower vent areas) are identical. The external environment is 
windless and of uniform temperature.

a. The total area of the high-level vent in Figure 1 is made smaller compared to the total area of the low-level vents. Please draw arrows to indicate how you would expect the air to flow through the building in Figure 1 .

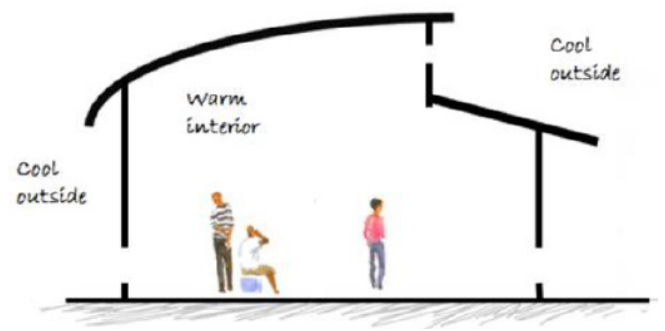

Figure 1.

b. The total area of the high-level vent in Figure 2 is made very large compared to the total area of the low-level vents. Please draw arrows to indicate how you would expect the air to flow through the building in Figure 2 .

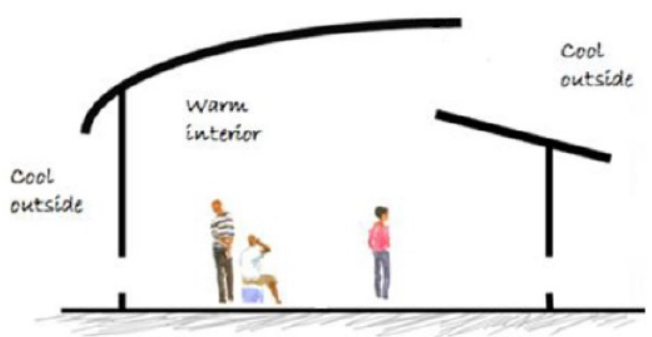

Figure 2.

15. Figure 3 shows a typical example of a 'box-like' representation of a room as used in the analyses of building ventilation in scientific journals.

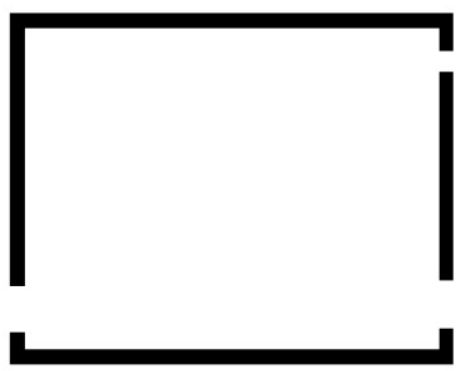

View in section

Figure 3. 
a. Is it clear to you why Figure 3 can represent the building in Figure 1 (shown in question 14a.)?

$\square$ Yes $\square$ No

State your reason:

b. Would you regard the schematic in Figure 3 to be disrespectful of architects' design aspirations?

$\square$ Yes $\square$ No

If yes, how would you like Figure 3 to be visually represented? Provide a sketch below.

Theme 6: Perceived barriers to natural ventilation design

16. Do you think the quantity of information regarding natural ventilation design is too overwhelming, making it difficult for you as an architect to choose the resources and/or options to use?

$\square$ Yes $\square$ No

17. Do you think the quality of information regarding natural ventilation design is not tailored to the specific needs of architects?

$\square$ Yes $\square$ No

18. Do you think ventilation requirements set by the building regulations and standards are too stringent?

$\square$ Yes $\square$ No

If 'YES', do you think the strict ventilation requirements, set by the building regulations and standards, make it difficult for you as an architect to pursue a natural ventilation design option?

$\square$ Yes $\square$ No

19. Do you perceive natural ventilation as unpredictable and unreliable as it may not meet ventilation and thermal comfort requirements?

$\square$ Yes $\square$ No

20. Do you perceive inner city pollution and noise as barriers to natural ventilation design?

$\square$ Yes $\square$ No 
21. Do you think designing a naturally ventilated building restricts your freedom and creativity as an architect?

$\square$ Yes $\square$ No

State your reason:

\section{Theme 7: Expected future use}

22. In the next 5-10 years, would you like to see more buildings using natural ventilation as a low-energy strategy?

$\square$ Yes $\square$ No

State your reason:

\section{Theme 8: Desirable design guidance for architects}

23. If a design guide was to be written specifically for architects on natural ventilation...

a. What subjects would you want to read about or have included? (Tick all that apply)

$\square$ How to size openings for natural ventilation

$\square$ How to design a building that uses night purge (i.e. flushing of warm air from a building/ space at night)

$\square$ How to optimise the use of thermal mass and wind effects

$\square$ How to size and locate openings to make the best use of wind and stack effects

$\square$ Other

State subject:

b. Which of the following presentation styles would you think is ideal? (Tick all that apply)

$\square$ Diagrams, pictures and descriptions that impart visual information

$\square$ Mathematical equations and calculation examples to show how these formulae are used in practice

$\square$ Design graphs and data sheets; specific parameters can be read off the graphs to acquire the information that is needed in a natural ventilation design

$\square$ Checklists to help recognise necessary tasks/ design actions and decisions etc. 
c. How detailed would you prefer the design guide to be? (Choose one option)

$\square$ A short and concise guide with instructions on precisely how to design, e.g. simple steps on how to size openings

$\underline{\text { OR }}$

$\square$ A lengthy guide in which the instructions are supplemented with detailed reasoning and arguments for the instructions developed

State the reason for your choice in (c):

24. Where would you like to see the design guide published? (Tick all that apply)

$\square$ In a series of research papers published in international journals Please state type/name:

$\square$ In RIBA books

$\square$ In architectural digest(s)

Please state type/name:

$\square$ In a stand alone book, e.g. 'Natural Ventilation for Architects'

$\square$ Other

Please state type/name:

25. Any additional comments? 